OPEN ACCESS

Edited by:

Ruth Grene,

Virginia Tech, United States

Reviewed by:

Charu Lata,

National Botanical Research Institute

(CSIR), India

Jitender Giri,

National Institute of Plant Genome

Research (NIPGR), India

*Correspondence:

Pratap K. Pati

pkpati@yahoo.com

${ }^{\dagger}$ Present address:

Isha Sharma,

Vlaams Instituut voor

Biotechnologie-UGent Center for

Plant Systems Biology, Ghent

University, Ghent, Belgium

Specialty section:

This article was submitted to

Plant Abiotic Stress,

a section of the journal

Frontiers in Plant Science

Received: 08 August 2017 Accepted: 05 December 2017 Published: 20 December 2017

Citation:

Sharma I, Kaur N and Pati PK (2017) Brassinosteroids: A Promising Option in Deciphering Remedial Strategies for Abiotic Stress Tolerance in Rice.

Front. Plant Sci. 8:2151.

doi: 10.3389/fpls.2017.02151

\section{Brassinosteroids: A Promising Option in Deciphering Remedial Strategies for Abiotic Stress Tolerance in Rice}

\author{
Isha Sharma ${ }^{\dagger}$, Navdeep Kaur and Pratap K. Pati* \\ Department of Biotechnology, Guru Nanak Dev University, Amritsar, India
}

Rice is an important staple crop as it feeds about a half of the earth's population. It is known to be sensitive to a range of abiotic stresses which result in significant decline in crop productivity. Recently, the use of phytohormones for abiotic stress amelioration has generated considerable interest. Plants adapt to various environmental stresses by undergoing series of changes at physiological and molecular levels which are cooperatively modulated by various phytohormones. Brassinosteroids (BRs) are a class of naturally occurring steroidal phytohormones, best known for their role in plant growth and development. For the past two decades, greater emphasis on studies related to BRs biosynthesis, distribution and signaling has resulted in better understanding of BRs function. Recent advances in the use of contemporary genetic, biochemical and proteomic tools, with a vast array of accessible biological resources has led to an extensive exploration of the key regulatory components in BR signaling networks, thus making it one of the most well-studied hormonal pathways in plants. The present review highlights the advancements of knowledge in BR research and links it with its growing potential in abiotic stress management for important crop like rice.

Keywords: rice, phytohormones, brassinosteroids, abiotic stress, stress amelioration, reactive oxygen species, signal transduction

\section{INTRODUCTION}

Rice is an important food crop, produced in many countries worldwide and feeding significant portions of the global population (IRRI, 2006; Kaur and Pati, 2017). More than half of the world's population acquires $80 \%$ of their calories from rice $(\mathrm{FAO}, 2008)$. However, its cultivation and yield is under tremendous pressure due to adverse environmental stresses. It is sensitive to a range of abiotic stresses, including salinity, drought, submersion and cold (Wani and Sah, 2014). It is estimated that worldwide around $30-60 \%$ of yield loss per annum in rice occurs due to various kind of stresses (Seo et al., 2011). To reduce the impact of these stresses in rice plants, in depth analysis of the associated responses to stresses have been given priority in the past (Kumar et al., 2013; Mizoi and Yamaguchi-Shinozaki, 2013).

For many decades, conscious efforts have been made to overcome negative effects of environmental stresses such as remedial water management, use of tolerant cultivars and divergent cultural practices (Parry et al., 2005; Neumann, 2008). Other approaches adopted involve plant breeding which create useful genetic variations to withstand a specific environmental stress 
(Hu and Xiong, 2014; Mickelbart et al., 2015). However, the process of breeding tolerant rice cultivars is very slow owing to numerous concerns including a paucity of knowledge of the mechanisms underlying tolerance, intricacies of the traits associated with the stress, inadequate selection criteria and absence of rigorous, consistent and reproducible screening methodologies (Gregorio et al., 2002). Moreover, attempts to improve stress tolerance through conventional plant breeding methods are time consuming, laborious and dependent on existing genetic variability. Classical genetics suggests that stress tolerance is generally a multigenic trait (Barton and Turelli, 1990; Hoffmann and Parsons, 1991) and therefore, it is difficult to obtain precise control of the traits that the host plant will express or consistent genetic stability in subsequent generations. Further, the complexity of traits involved in tolerance of a particular stress and the coexistence of various types of environmental challenges in nature, exacerbates the magnitude of the problem and significantly impedes progression in the development of tolerant varieties (Ismail et al., 2007). Progress in the field of molecular biology has resulted in identification and use of molecular markers to expedite the breeding program for conferring abiotic stress tolerance in plants (Gregorio et al., 2013; Ismail and Horie, 2017). However, it was observed that the introgression of genomic segments (Quantitative trait loci, QTLs) attributed to stress tolerance might also be responsible for bringing undesirable traits from the donor plants (BhatnagarMathur et al., 2008). To overcome these problems, development of genetically engineered plants by insertion of stress responsive and putative tolerance conferring genes has attracted a lot of attention worldwide (Bhatnagar-Mathur et al., 2008; Saad et al., 2013). There are several reports of use of gene transfer technology to alter the accumulation of osmoprotectants, increase the production of chaperones, enhance the free radical scavenging and exclusion, or compartmentalization of ions employing competent transporter and symporter systems to confer abiotic stress tolerance in rice (Garg et al., 2002; Chen et al., 2008; Zhao et al., 2009; Liu A.L. et al., 2013; Todaka et al., 2015). Recently, there has been a paradigm shift from gene centric to genome centric approach in crop improvement program. In this regard, manipulation of the cellular regulatory machinery containing transcription factors are given preference over the attempts to insert "single-action" genes (Khong et al., 2008). However, evaluation of transgenic plants for stress tolerance, and prediction/detection of the physiological effect of the insertions at the whole plant level remains as a major challenge. Besides this, the transgenic approach to offer tolerance to plants faces skepticism due to various concerns such as the possible impact of transgenic plants on biodiversity, cross-contamination of germplasm with transgenic material and lack of public acceptance of transgenic food due to potential health risks. In this scenario, escalating the stress-resistance of plants through non-transgenic means could be one of the most effective measures to solve the worldwide problem (Sharma et al., 2015; Divi et al., 2016). Under these circumstances, scientists are being compelled to develop innovative approaches which could be widely accepted to public for global agriculture. In this context, the essential role of phytohormones in stress regulatory processes of plant is being explored in various laboratories across the world. Although, phytohormones are usually synthesized at low concentration in plants, however, they control plethora of developmental events in a plant under normal conditions. Phytohormones control plant's functions by regulating their own biosynthesis, modulating their available pool for a particular action, or influencing various signaling cascades.

\section{BRS: A PROMISING PHYTOHORMONE IN ABIOTIC STRESS AMELIORATION}

Brassinosteroids are important phytohormones due to their versatile roles in plants (Vardhini, 2016; Wei and Li, 2016; Yusuf et al., 2017). They are plant-specific steroidal hormones which are perceived by a cell-surface receptor family of leucine-rich repeat receptor kinases BRASSINOSTEROID INSENSITIVE 1 (BRI1), which interacts with co-receptor BRI1 ASSOCIATED RECEPTOR KINASE 1 (BAK1) and undergoes a series of phosphorylation and dephosphorylation events to transduce information to the nucleus that results in the regulation of expression of several hundred genes involved in diverse physiological functions (Sharma et al., 2013c; Belkhadir and Jaillais, 2015; Nakamura et al., 2017). BRs regulate different forms of plant growth and development including xylem differentiation, photomorphogenesis, cell elongation and seed germination (Vriet et al., 2012; Zhang et al., 2014). However, recently, there has been a prominent increase in their application in agricultural processes to improve crop productivity under stress and native conditions (Vriet et al., 2012; Zhang et al., 2014; Marakli and Gozukirmizi, 2016; Liu et al., 2017). Keeping in mind the scope of BRs in agriculture, in the past few years, efforts have been undertaken to gain better insights into BR metabolism and signaling (Belkhadir and Jaillais, 2015). Although several studies have been conducted on the potential of BRs for enhancing stress tolerance (Zhang et al., 2014; Ahammed et al., 2015; Sharma et al., 2015; Hegazi et al., 2017; Wang et al., 2017), yet their underlying mechanisms of action remain elusive. This could be due to the integration of BR signals in many other signaling networks linked to stress mitigation (Divi and Krishna, 2010; Ahammed et al., 2015; Divi et al., 2016). The present review discusses some of the possible mechanisms through which BRs could modulate stress responses in plants. The knowledge gained from this can be extrapolated for deciphering remedial strategies for abiotic stress tolerance in hugely important crops like rice.

\section{BRS MEDIATED STRESS RESPONSES OCCUR AT DIFFERENT LEVELS OF ORGANIZATION}

The process of a plant responding appropriately to environmental cues first requires that the plant senses the changing environment. Due to the complex nature of stress, the likely involvement of multiple sensors for perception of signals is predicted. The signal transduction pathways which are activated after the perception of signals ultimately activates stress responsive genes 
thus generating the initial stress response. In this update we integrate the BRs signals with various abiotic stress responses which presumably occur at different levels (Figure 1).

\section{ROLE OF BRS AT THE CELLULAR LEVEL}

\section{Changes in Cell Cycle and Cell Division}

The adverse effect of stress on plant growth and development could be the consequence of inhibition of the cell proliferation and cell expansion (Skirycz et al., 2011). BRs govern plant growth by regulating the process of cell expansion and division (Hacham et al., 2011; Zhiponova et al., 2013) as was clearly demonstrated by utilizing the Arabidopsis BR-deficient mutant, constitutive photomorphogenesis and dwarfism (cpd) (Noguchi et al., 1999). cpd leaf blades size was reduced in size due to decrease in cell size and number. This leaf phenotype of $c p d$ was associated with prolonged cell division phase and delayed differentiation as revealed by tissue-specific marker gene expression. From this experiment, it was realized that BR production and its receptordependent signaling is important to differentially regulate cell division and expansion in the leaf. Since then, many reports have substantiated the role of BRs in the process of cell division and cell cycle regulation (Sun et al., 2010; Clouse, 2011; Hacham et al., 2011; Hu et al., 2017). Cell proliferation is known to be modulated by a class of protein kinases that include cyclindependent kinase (CDK) and cyclin which together controls the cell cycle (Kitsios and Doonan, 2011). In case of abiotic stress, the reduced expression of $C D K$ genes and increased expression of their inhibitors (ICK1, EL2) to down-regulate their mitotic activity has been observed (Peres et al., 2007; Fu et al., 2008; Rodríguez et al., 2013). But investigations into the effect of BRs on cell cycle markers clearly suggests that BRs induce the expression of various cell cycle related genes ( $C Y C A, C Y C B$, CYCD3; 1, CYCD3;2) encoding cyclin dependent kinases (CDKs) and cyclophilins that play critical role in cell cycle regulation, cell proliferation and differentiation (Fu et al., 2008). Moreover, the BR activated transcription factor, BRI1-EMS-SUPPRESSOR 1 (BES1) regulates the expression of $U$-type cyclin CYC U4;1 and GSK-kinase to control leaf erectness by reducing the proliferation of the abaxial sclerenchyma cell number of rice lamina joints (Sun et al., 2015). Owing to the fact that rice leaf erectness improves photosynthetic efficiency, leading to enhanced yield and reduced leaf transpiration under drought stress (Lang et al., 2004), the unique role that BRs play in controlling leaf erectness makes them a key determinant for rice architecture and yield under stress conditions.

Transcript profiling and chromatin-immunoprecipitation microarray (ChIP-chip) analysis has identified a large set of genes involved in cell elongation and growth that are direct targets of the BR-regulated transcription factor BRASSINAZOLE RESISTANT 1 (BZR1) (Sun et al., 2010; Hacham et al., 2011). BRs also mediate cell cycle progression through regulation of various key transcription factors both under stressful- and normal-growth conditions. BRs regulate the R2R3-type MYB transcription factor, MULTIPASS (OsMPS), which is induced under salinity stress and negatively regulates growth by reducing cell size (Schmidt et al., 2013). Another R2R3-MYB transcription factor, BRAVO (BRASSINOSTEROIDS AT VASCULAR AND ORGANIZING CENTER) that modulates plant stem cell

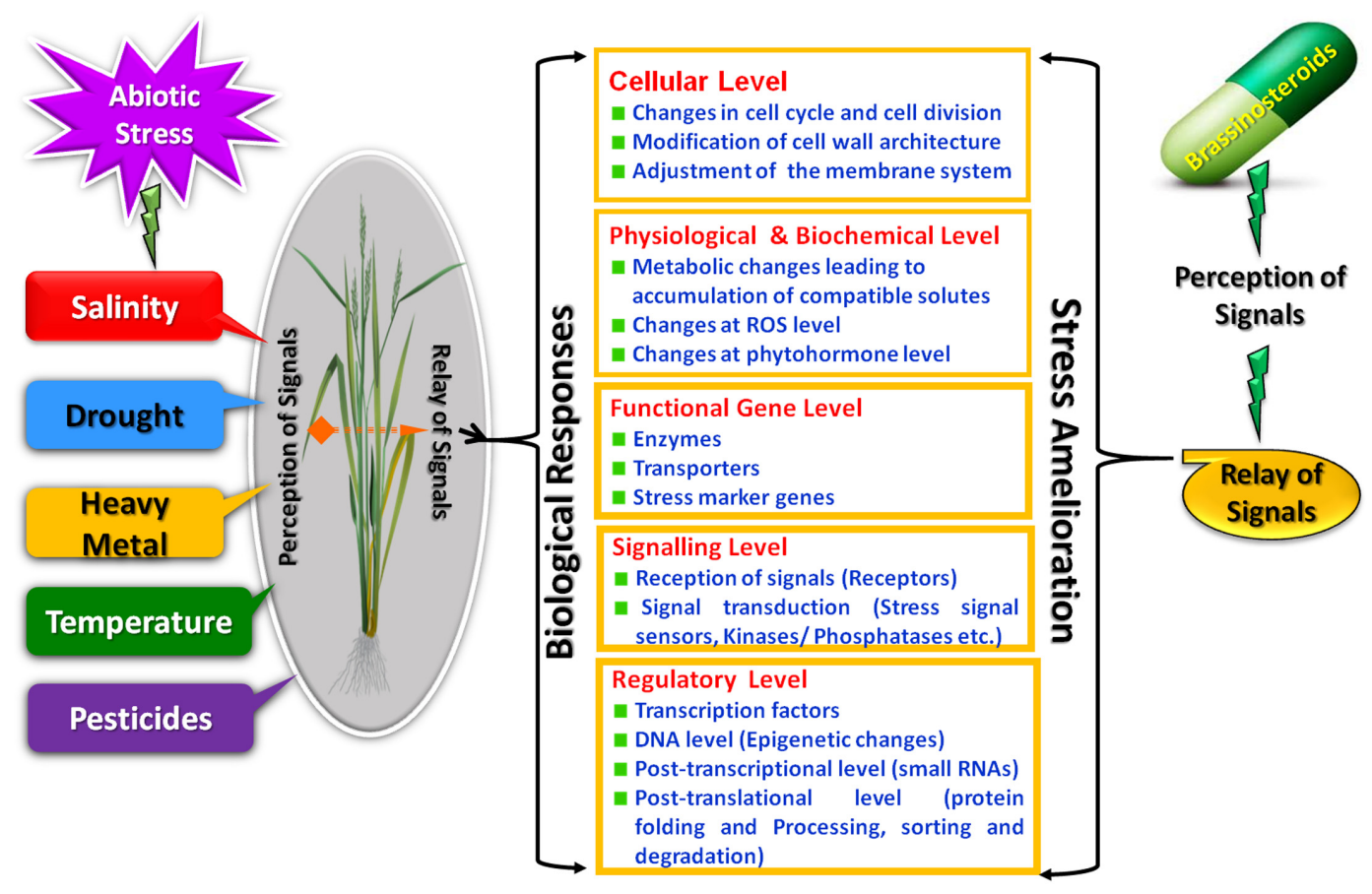

FIGURE 1 | Brassinosteroids mediated remedial strategies for abiotic stress responses. 
quiescence is regulated by BRs through the interaction with BES1. BRAVO is a cell-specific repressor of quiescent centre cell (QC) divisions in the primary root of Arabidopsis and counteracts BRmediated cell division in the QC cells (Chaiwanon and Wang, 2015). BR activated transcription factor, BES1 physically interacts with BRAVO to repress its activity thus modulating the divisions of QC of the root stem cell (Vilarrasa-Blasi et al., 2014). Since the non-dividing cells in QC can initiate cell division under the effect of stress related-phytohormone and contribute to plant longevity, $\mathrm{BRs}$ regulation of the QC seems yet another mechanism toward providing stress acclimatization in plants (Heyman et al., 2014). As the rice QC closely resembles that of Arabidopsis (Ni et al., 2014), it is extrapolated that a similar mode of regulation under the effect of BRs could be expected in case of rice under stress conditions. It has been established that BRs are not only required for cell division, differentiation and expansion in the leaf, but the balance between differentiation and proliferation depends on BRI1-mediated signaling and BR levels in a temporal and spatial manner (González-García et al., 2011; Zhiponova et al., 2013). Under environmental stress, the meristematic activity in rice is maintained by a regulatory protein RICE SALT SENSITIVE 1 (RSS1) which contributes to the vigor of meristematic cells and their viability. It regulates the G1-S transition, by interacting with protein phosphatase 1 facilitated by the phytohormone cytokinin (Ogawa et al., 2011). Though unlike cytokinin, a direct link between BRs and RSS1 has not been established, BRs alone or in crosstalk with cytokinin may be involved in regulating meristematic function in rice through the RSS1 protein and hence could be a very interesting mechanism leading to stress tolerance to explore further.

\section{Modification of Cell-Wall Architecture and Adjustment of Membrane System}

During various stressful conditions (freezing, drought, salt stress etc.), fluctuating water or ionic status in the ambient environment poses one of the most critical and existential challenges for preservation of functionality of cellular membranes (plasma membrane and enodomembranes) of the plant cell (Golldack et al., 2014). It has been observed that BR leads to the modification of cell-wall architecture and adjustment of the membrane system thus providing a first line of defense against environmental stresses to plants (Clouse, 1996). BR signaling plays a central role in plant morphogenesis, as evidenced by various $\mathrm{BR}$ responsive genes linked to cell wall and the extreme developmental defects of BR mutants (Kauschmann et al., 1996). On the contrary, an enhanced BR level or activity can significantly increase plant growth, biomass accumulation, and seed yield (Salas-Fernandez et al., 2009). Global expression profiling has revealed that BRs induce the expression of several cell wall extension and loosening enzymes, e.g., xyloglucan endotransglucosylase/hydrolase (XTHs), pectin lyase-like (PLLs) and expansins (EXPs) to increase cell expansion (Uozu et al., 2000; Guo et al., 2009). BES1 interacts with the rice MYB transcription factor, OsMPS to regulate the expression of expansins (OsEXPs) and endoglucanases (OsGLUs) serving as an integrative link in the crosstalk between phytohormones and the environment to regulate adaptive growth (Schmidt et al., 2013). Pectin methylesterases (PMEs) play important roles in cell wall expansion and serve as a crucial determinant of stress tolerance in rice (Yang et al., 2013). BRs signaling have been found to be indispensable for increasing PME abundance, leading to increased activity, by modulating the expression of AtPME41 that is associated with the stress resistance mechanism (Qu et al., 2011; Wolf et al., 2012). Interference with PMEs activity (genetic or pharmacological) causes decreased pectate in the cell wall which results in stimulation of the BRI1 receptor through an unidentified feedback mechanism resulting in a compensatory up-regulation of wall remodeling agents including PMEs to protect the plant against the break-down of cell wall integrity. Recently, the primary element of this feedback loop, a RECEPTOR-LIKE PROTEIN (RLP44), has been identified (Wolf et al., 2014). RLP44 activates BR signaling through direct interaction with the regulatory $\mathrm{BR}$ co-receptor BAK1. Thus, RLP44 integrates the hormone signaling with cell wall surveillance to mediate wall integrity and growth. Furthermore, several genes whose products are responsible for maintaining cell wall architecture are the direct downstream targets for BR-activated transcriptional factors. One of them is the CELLULASE SYNTHASE A (CESA) family encoding a glycosyltranferase that is crucial for cellulose synthesis and is differentially regulated under various stresses (Guerriero et al., 2014). BES1 binds to the promoter regions of different sets of CESA genes to regulate differential responses in primary and secondary growth (Xie et al., 2011).

\section{ROLE OF BRs AT PHYSIOLOGICAL AND BIOCHEMICAL LEVEL}

Abiotic stress can confer serious damage to the photosynthesic machinery. It can damage components of the photosynthetic (PTS) apparatus directly, which leads to an imbalance in photosynthetic redox signaling resulting in the inhibition of PSII repair leading to photoinhibition (Ashraf and Harris, 2013; Gururani et al., 2015). Several studies suggest that BRs have a positive effect on the photosynthetic machinery of plants both under stress and non-stressed conditions. Exogenous application of BRs is known to alleviate photoinhibition by significantly enhancing the photochemical efficiency of PSII, the quantum efficiency of PSII photochemistry and photochemical quenching coefficient (Xia et al., 2006, 2009; Ahammed et al., 2015). BRs also significantly enhance the net photosynthetic rate, intercellular $\mathrm{CO}_{2}$ concentration, transpiration rate and stomatal conductance under stress (Farooq et al., 2010; Hayat et al., 2012). BRs enhance chlorophyll content and reduce the activity of chlorophyllase responsible for catabolism of chlorophyll pigment under abiotic stress (Bajguz, 2011; Hayat et al., 2012; Sharma et al., 2015). Treatment of cucumber plants with BRs up-regulated, while brassinozole (biosynthetic inhibitor of BRs), down-regulated RuBisCO and photosynthetic proteins (Xia et al., 2009). BRs induce the recovery of the photosynthetic apparatus of plants from 
cold stress, by eliciting the enzymes of Calvin cycle and antioxidant defense system (Jiang et al., 2013). BR application enhances ALTERNATIVE OXIDASE (AOX) activity in a RBOHdependent manner. The enhanced AOX then contributes to balancing of chloroplast-to-mitochondria electron transfer by dissipation of excess photosynthetic reductant leading to decreased ROS accumulation and increased protection of photosystems (Deng et al., 2015).

During abiotic stress, anatomical features like stomatal and epidermal pores which facilitate gas exchange are regulated to optimize water-use efficiency and photosynthesis for stress survival. Various studies have revealed that BRs integrate with environmental signals to regulate stomatal aperture, one of the most important factors in dehydration- and salt-stress acclimatization preventing excessive water loss (Gudesblat et al., 2012; Daszkowska-Golec and Szarejko, 2013). Exogenous application of BRs promotes stomatal closure as well as inhibits stomatal opening in epidermal peels of Vicia faba inhibiting inwardly rectifying $\mathrm{K}^{+}$channels and thus reducing guard cell uptake of $\mathrm{K}^{+}$which is required for stomatal opening (Haubrick et al., 2006). Essentially, low concentration of BRs activate the RESPIRATORY BURST OXIDASE HOMOLOG $(\mathrm{RBOH})$ genes to transiently relay hydrogen peroxide $\left(\mathrm{H}_{2} \mathrm{O}_{2}\right)$ signal for balancing the cellular redox status of glutathione that is critical for BR-induced stomatal opening. While at higher concentration of BRs, the signal for $\mathrm{H}_{2} \mathrm{O}_{2}$ production is prolonged which facilitates $\mathrm{ABA}$ signaling and stomatal closure (Xia et al., 2014). BRs have also been known to regulate transcription factors YODA (YDA) and MAPK to reduce stomatal conductance and this could serve as one of the mechanism for BRs induced salt- and drought-tolerance (Kim et al., 2012). This work demonstrates that BR negatively regulates stomatal development by inhibiting BRASSINOSTEROID INSENSITIVE 2 (BIN2)-mediated phosphorylation and inactivation of YDA that leads to the activation of the MAP kinase pathway.

A common defensive mechanism against a range of stresses in rice is the accumulation of compatible solutes like proline, fructans, polyamines, myo-inositol and sugar alcohols (Kumar et al., 2013). These osmoprotectants facilitate a range of stress tolerance mechanisms involving scavenging of reactive oxygen species (ROS), maintenance of cellular turgor by adjusting osmotic balance and protection and stabilization of proteins and cellular structures. Studies show that over-expression of the biosynthetic enzyme PYRROLINE-5-CARBOXYLATE SYNTHETASE1 (P5CS1) in plants result in increased proline accumulation and enhanced stress acclimatization (Yamada et al., 2005), whereas knocking out P5CS1 resulted in impaired stress-induced proline synthesis resulting in salinity-hypersensitive plants (Szekely et al., 2008). In many studies, BRs have been shown to induce the accumulation of compatible solutes under various stress conditions which is often associated with improved stress survival (Sharma et al., 2012, 2013a; Kumar et al., 2013). Nevertheless, salt stress induced hypersensitivity of the BRs biosynthetic (det-2) and signaling mutants (bin-2) has been linked to the decreased expression of proline biosynthetic gene (P5CS1) and reduced proline levels which confirms the importance of BRs for inducing proline levels in stress resistance (Zeng et al., 2010). In one study, a tyrosine (Y831F) mutant of BRI1-Flag was shown to enhance the production of proline in the absence of water or osmotic stress. The authors suggest that in the absence of stress, proline may act as a signaling molecule to modify mitochondrial function and modulate gene expression resulting in an increased ability of plants to tolerate stress (Szabados and Savoure, 2010), further insinuating that the regulation of phosphorylation at the BRI1 receptor complex may be involved in enhancing abiotic stress tolerance in plants (Oh et al., 2011).

\section{Maintenance of Redox Potential of the Cell}

Responses of plants to various types of stresses are often associated with generation of ROS, suggesting the role of ROS as a common element in plant stress signaling pathways (Liu et al., 2010; Baxter et al., 2013; Kaur et al., 2016a,b). An increasing body of evidence suggests that ROS action is bimodal: high levels of ROS cause cell death while at lower cellular levels; they play regulatory roles in plant stress responses (Baxter et al., 2013). BR-induced stress tolerance is often associated with enhanced accumulation of ROS, as ROS increased steadily with increasing concentration of exogenously applied BR (Jiang et al., 2012a,b). BRs induce $\mathrm{H}_{2} \mathrm{O}_{2}$, that can behave as a signaling molecule in response to different stimuli, in turn activates MAPK that induces NADPH oxidase to self-propagate cellular $\mathrm{H}_{2} \mathrm{O}_{2}$ resulting in a positive amplification loop of the signal. The resultant build-up of $\mathrm{H}_{2} \mathrm{O}_{2}$ level up-regulates the activities of stress response related proteins, such as antioxidant enzymes, dehydrins, transcription factors, heat shock proteins induced by low-temperature and pathogenesis-related proteins to scavenge ROS, leading to suppression of ROS levels (Xia et al., 2009, 2010; Zhang et al., 2010; Cui et al., 2011; Zhu et al., 2013). Moreover, BRs cannot undergo long distance transport but they induce systemic stress tolerance by enhancing the $\mathrm{H}_{2} \mathrm{O}_{2}$ production (Xia et al., 2009, 2011). Inhibition of NADPH oxidase or addition of a $\mathrm{H}_{2} \mathrm{O}_{2}$ scavenger results in significant lowering of systemic $\mathrm{H}_{2} \mathrm{O}_{2}$ accumulation leading to reduced tolerance to photooxidative stress in leaves. In tomato, BRs led stress tolerance through increased apoplastic $\mathrm{H}_{2} \mathrm{O}_{2}$ and increased activation of MPK1/2 was hindered in $\mathrm{RBOH1}$-, $M P K 1 / 2$ - and MPK2- silenced plants but not in $M P K 1$ silenced plants revealing a relatively more important role of MPK2 than MPK1 in BR-induced apoplastic $\mathrm{H}_{2} \mathrm{O}_{2}$ accumulation (Nie et al., 2013). Similarly, in Nicotiana benthamiana, silencing of $R B O H$ compromised the BR induced AOX activity and hence reduced ROS scavanging making the plant more susceptible to abiotic stresses (Deng et al., 2015). In a recent study, BR treatment was unable to elicit antioxidant defense in the rice and maize CALCIUM/CALMODULIN-DEPENDENT PROTEIN KINASE (CCaMK) mutants. It was found that BR application results in increase in cytosolic $\mathrm{Ca}^{(2+)}$ concentration followed by increase in activity of CCaMK which further enhanced the BR-induced increase in cytosolic $\mathrm{Ca}^{(2+)}$ concentration thus forming a 
positive feedback loop of $\mathrm{Ca}^{(2+)}$ and CCaMK in BR signaling (Yan et al., 2015). ABA has also been demonstrated to be intricately involved in BR-orchestrated antioxidant defense via ZmMAP65-1a as inhibition of ABA biosynthesis reduces the expression and activity of ZmMAP65-1a (Zhu et al., 2015). The BR-induced pulse of $\mathrm{H}_{2} \mathrm{O}_{2}$ production via NADPH oxidase results in enhanced $\mathrm{ABA}$ biosynthesis, which results in further escalation of $\mathrm{H}_{2} \mathrm{O}_{2}$ levels leading to prolonged stress tolerance (Zhou et al., 2014). There are many reports showing BRinduced stress tolerance by regulating the activity and expression of antioxidant enzymes (Cui et al., 2015; Jin et al., 2015; Sharma et al., 2015). This is further supported by the fact that reduced BR biosynthetic mutant plants have reduced ratios of glutathione/glutathione disulfide (GSH/GSSG) and ascorbic acid/dehydroascorbic acid (AsA/DHA), while BR treatment enhances the activity of antioxidant enzymes, expression of various defense-related genes and the GSH/GSSG and AsA/DHA ratios (Sharma et al., 2012, 2013a,c; Zhou et al., 2014). Studies suggest that in rice, $\mathrm{BR}$ results in a concentration dependent increase in the expression and activity of antioxidant enzymes both under stress and control conditions (Sharma et al., 2012, 2013b,c; Sharma, 2014). BRs have also been shown to reduce the residues of commonly used pesticides by $30-70 \%$ in various crops including rice due to BRs induced enhanced glutathione metabolism and glutathione S-transferase (GST) activity via a RBOH 1-dependent pathway (Xia et al., 2006, 2009; Zhou et al., 2015).

Nitric oxide (NO) is another ubiquitous and key signaling molecule involved in various vital processes such as plant ion homeostasis, hormone responses, programmed cell death (PCD), disease resistance and responses to abiotic stress (Zhao et al., 2004). It is identified as a downstream signaling molecule of $\mathrm{H}_{2} \mathrm{O}_{2}$ in $\mathrm{BR}$ signaling and plays a critical role in BR-induced stress tolerance by modulating ROS scavenging network. Inhibition of NO production is found to inhibit BR-induced stress tolerance and partly blocks BR-induced expression and activities of various antioxidant enzymes (Cui et al., 2011; Zhang et al., 2011). Gene silencing or chemical inhibition of nitrate reductase (NR) and nitric oxide synthase (NOS)-like enzyme inhibits the BRs-induced alternative respiratory pathway and thus decreased plant's resistance to salt stress (Zhu et al., 2015). On the other hand, BRs induce NO production in a ROS dependent manner via both NOS-like and nitrate/nitrite dependent enzymatic routes (Zhang et al., 2010; Yang et al., 2013) and NO in turn mediates induction of antioxidant genes, for mitigating oxidative stress conditions (Zhang et al., 2010). Moreover, the $\mathrm{NO} / \mathrm{H}_{2} \mathrm{O}_{2}$ accumulated under $\mathrm{BR}$ treatment activates ABA biosynthesis which results in further enhancements of $\mathrm{H}_{2} \mathrm{O}_{2}$ accumulation and prolonged stress tolerance (Zhang et al., 2011). Additionally, BR induces ethylene synthesis, thereby activating GTP-binding protein $\mathrm{G} \alpha$, that promotes Arabidopsis RESPIRATORY BURST OXIDASE HOMOLOG F (AtRBOHF)dependent $\mathrm{H}_{2} \mathrm{O}_{2}$ production. It further elicits enhanced $\mathrm{NO}$ biosynthesis through NIA1 protein, augmenting signals for stomatal closure (Shi et al., 2015).

\section{Changes at the Phytohormone Level}

Phytohormones play a central role in various plant processes involved in adaptation to environmental changes by regulating growth, nutrient allocation and source/sink interactions (Peleg and Blumwald, 2011; Tiwari et al., 2017). Abiotic stress differentially modulates phytohormonal levels by regulating their biosynthesis as well as their metabolism (Maruyama et al., 2014; Saini et al., 2015). BR signaling is known to positively regulate abiotic stress tolerance both by exogenous application of BRs (Divi et al., 2010; Sharma et al., 2013c; Wani et al., 2016) as well as by genetic deactivation of negative regulators of the BR signaling pathway (Koh et al., 2007). However, BR crosstalk with other hormones at the level of biosynthesis, signal transduction and transcriptional regulation and thus, the stress ameliorative abilities of BRs are partly derived from BR interactions with other stress related hormones (Divi et al., 2010; Choudhary et al., 2012b; Saini et al., 2013; Yusuf et al., 2017). The biosynthetic-, signaling- and constitutively active-mutants impinging on ABA, ET, JA, and SA were evaluated for heat and salinity tolerance in untreated and BR-treated samples (Divi et al., 2010). BRconferred stress tolerance was observed to be enhanced in the ABA-deficient aba1-1 mutant than wild type. Hypersensitivity of the ethylene-insensitive2 (ein2) mutant to salt stress was rescued by BR, but BR-induced thermo-tolerance was minimal in SA genotypes non-expressor of pathogenesis-related genes 1-1 (npr1-1) (signaling defective for SA-mediated systemic acquired resistance (SAR). Thus, NPR1 which plays a key role in SA-mediated SAR was found to be critical to BR-mediated increase in hyperthermal and salt-tolerance. However, BRs are also known to mitigate stress-caused oxidative damage by inducing ethylene biosynthesis (Wei et al., 2015). Upon BR stimulated induction, ethylene acts synergistically with the BRs to induce elevated $\mathrm{H}_{2} \mathrm{O}_{2}$ to enhance the level of AOX resulting in efficient ROS scavenging for improved stress tolerance. Similar evidence has been obtained where combined treatment of BRs with other hormones like $\mathrm{ABA}, \mathrm{SA}$, and polyamines result in a synergistic increase in stress protective effects as compared to individual hormone treatment (Choudhary et al., 2012a; Hayat et al., 2012). Microarray data also shows that BRs share overlapping regulation of many genes with other hormones like ABA, Jasmonic acid and auxin (Vert et al., 2008; Sun et al., 2010; Divi et al., 2016). However, this coordinate regulation is complex. For example, the BR interaction with ABA is multi-faceted. BR-induced accumulation of ABA content was observed in Chlorella vulgaris cells and in canola (Brassica napus) plants exposed to hyperthermal stress (Kurepin et al., 2008; Bajguz, 2009). Chemical inhibition of ABA biosynthesis led to a marked reduction in BR-induced stress tolerance (Liu et al., 2009; Zhang et al., 2011), whereas the study cited above showed ABA biosynthesis mutants had enhanced stress tolerance upon BRs application, albeit in different species (Divi et al., 2010). These reports exemplify the conflicting nature of interaction between BRs and ABA under stress. A recent study attempts to answer these discrepancies based on BRs and ABA induced $\mathrm{H}_{2} \mathrm{O}_{2}$ signaling under abiotic stress (Yang et al., 2014). The authors argue that continuous supply of BRs to plants result in continuous $\mathrm{RBOH} 1$ induction and $\mathrm{H}_{2} \mathrm{O}_{2}$ production 
without the aid of ABA, while ABA biosynthesis becomes critical for prolonged tolerance to stress in BR-induced pathways in plants. $\mathrm{ABA}$ and $\mathrm{BRs}$ are also shown to act antagonistically on different targeted genes at or after BIN2 in BR signaling pathways and jointly fine-tune the growth of the plant when there is a competition for resources between stress responses and growth (Chung et al., 2014). Thus, under natural conditions, different hormonal signaling pathways undergo a crosstalk among themselves and among various stress signaling pathways in combinations to generate a customized stress response that is most suitable for the survival of plant under given environmental conditions.

Genetic and physiological studies have shown that BRs and auxin interact antagonistically in roots to maintain the spatiotemporal balance between stem cell division and differentiation required for optimal root growth (Chaiwanon and Wang, 2015). Interestingly, BRs have a dual effect of both delay and promotion of stem cell differentiation, depending on the site of their action. BR-induced genes mostly occur in epidermal cells of the basal meristem zone which also happen to be enriched with auxin related genes. While BR down-regulated genes occur in the stele of the apical meristem zone and thus regulate differential growth (Vragović et al., 2015). Similar integration of BRs signaling pathway with that of other phytohormones explains differential spatiotemporal context of brassinosteroid activity in a tissue and organ specific manner (Singh and SavaldiGoldstein, 2015).

BRs and GA work antagonistically to provide submergence tolerance in lowland rice plants (Schmitz et al., 2013). While floating- and deepwater-rice cultivars avoid submergence by exaggerated stem elongation, lowland rice cultivars have been demonstrated to have enhanced survival of flash-flooding episodes by repressing stem elongation. Repression of stem elongation is thought to provide reserves for maintenance of cellular homeostasis during the period of low gas exchange (Louis Setter and Vidonia Laureles, 1996). Exogenous BRs induce ancillary stabilization of the DELLA proteins and SLENDER RICE1 (OsSLR1), a GA signaling repressor resulting in reduced shoot elongation correlated with improved submergence tolerance. BRs also crosstalk with cytokinin to induce drought stress tolerance (Peleg et al., 2011). Enhanced expression of ISOPENTENYL TRANSFERASE, a key enzyme in cytokinin synthesis, the gene of which, when under the control of a drought inducible- or senescence inducible-promoter, resulted in increased tolerance to drought with concomitant increases in genes encoding proteins involved in both BR biosynthesis and signaling, suggesting a cross-talk between BRs and cytokinin leading to drought stress tolerance. A large number of BR regulated genes are also regulated by polyamines (spermidine) and simultaneous application of both phytohormones generate additive or synergistic effect to enhance heavy metal tolerance of radish plants relative to the application of each hormone individually. The resulting tolerance was partly attributed to regulation of genes involved in auxin and ABA metabolism under the combined application of BR and spermidine, which could be contributing toward improved seedling growth and normal functioning of several physiological processes, such as seed germination, regulation of stomata and embryogenesis(Choudhary et al., 2012a).

\section{ROLE OF BRS AT FUNCTIONAL GENE LEVEL}

Various genes have been identified in rice to be induced under abiotic stress. Functional annotation of these genes reveal that they are involved in various cellular processes, such as vesicle trafficking, signaling, cytoskeleton rearrangement, and biosynthesis of hormones and vitamins (Basu and Roychoudhury, 2014; Qian et al., 2015; Yang et al., 2015). Many of these gene products are also regulated by BR viz., molecular chaperones (heat shock proteins), cytoskeleton proteins (tubulin, actin), redox metabolism (dehydrins, glutathione-S-transferase) and hormonal biosynthesis and metabolism (ACC oxidase and allene-oxidase cyclase) (Deng et al., 2007; Sun et al., 2010; Divi et al., 2016) which play important roles in plant growth and development (Table 1). BR transcriptome analysis has identified abiotic stress-related alteration in transcription of JACALIN-RELATED LECTIN1-3 (JAC-LEC1-3), WRKY33, ACID PHOSPHATASE5 (ACP5) and a BR-RESPONSIVE-RECEPTORLIKE KINASE (BRRLK) (Divi et al., 2016). Genetic and chemical evidences have identified various important genes like $D W A R F$ AND LOW-TILLERING (DLT), LEAF AND TILLER ANGLE INCREASED CONTROLLER (LIC), DWARF1 (D1) and TAIHU DWARF1 (TUD1), CYP90D2/D2 which play crucial role in maintaining several features of rice architecture are also regulated by BRs during stress (Wang and Li, 2005; Li et al., 2013; Zhang et al., 2014). Recently, a rice microRNA, OsmiR397, has been shown to positively control rice grain size and yield by downregulating its target, OsLAC, which encodes a laccase-like protein that regulates BR sensitivity (Zhang et al., 2013). Another protein, TUD1, encodes a functional U-box E3 ubiquitin ligase has been reported to be an interactor of proteins OsD1/RGA1, which forms the alternate pathway for BR signaling in rice. In rice, gene products like heat shock proteins (OsHSP17.0 and OsHSP23.7) that are implicated in the proper folding, stabilization, maintenance and degradation of numerous proteins, are known to be up-regulated under abiotic stress conditions and have recently been found to be direct targets of BZR1/BES1 (Kagale et al., 2007; Shigeta et al., 2014). Amino-terminal and central parts of BES1 provide affinity for physical interaction with HSP90.3 in vitro. In addition to BES1 and BIN2 being binding partners of HSP90, BZR1 has been identified as a novel HSP90 target and thus signifies that HSP90 forms a complex with two major transcription factors in BR-mediated gene expression (Shigeta et al., 2015). Rice plants accumulate LATE EMBRYOGENESIS PROTEINS (LEA), which provide stress protection by preventing protein aggregation and resulting in stabilization of membranes, are also targeted by BR-signaling activated BES1 (Li et al., 2009; Duan and Cai, 2012). The transcript level of RESPONSIVE TO DESICCATION 29A (RD29A) and EARLY RESPONSE TO DEHYDRATION10 (ERD10) encoding LATE EMBRYOGENESIS PROTEINS are enhanced upon BR treatment (Kagale et al., 2007). Proteomic approaches have also identified 
several proteins which are important for BR-induced stress tolerance (Deng et al., 2007; Sharma et al., 2013c). ABSCISIC ACID STRESS RIPENING (ASR)-like protein and LIPOCALINS which play essential roles in signal transduction under cold stress; REMORIN, an important membrane skeleton protein which is associated with biotic- and abiotic-stress responses as well as drought-stress responsive-and dehydrin-proteins are some of the key proteins involved in BRs induced stress tolerance (Li B. et al., 2012). The protein level of FERRITIN, a ubiquitous multimeric iron storage protein which helps sequester excess free iron is induced under the effect of salt or brassinolide treatment in Arabidopsis (Sharma, 2014). It might be a mechanism not only for maintaining iron homeostasis but for prevention of the formation of hydroxyl radicals through the Fenton action as well and thus it might be helping maintain ion balance and general enzyme activity (Lobréaux et al., 1995) under stress conditions. An interesting study was performed on the SALT gene which is located on the SalTol QTL in rice and expressed highly under the effect of salinity (Sharma et al., 2013c; Sharma, 2014). While the expression of the $S A L T$ gene rose under salt treatment, its expression was severely reduced in rice seedlings co-treated with salt and BRs. The promoter region of the SALT gene revealed the presence of motifs such as ABRE (abscisic acid responsive element), MBS (a MYB binding site involved in droughtinducibility), LTR (involved in low-temperature responsiveness), that are implicated in different kind of stresses. Thus, the presence of these motifs in the SALT promoter and SALT'S regulation by BRs can be explored as one of the mechanisms by which BRs induced stress protection to a multitude of extrinsic factors (Sharma, 2014). Furthermore, manipulation of BR biosynthetic genes has also provided evidence for the role of endogenous BRs in stress tolerance. Application of brassinozole, the specific inhibitor of the DWARF4 (DWF4), a protein involved in BR-biosynthesis results in plants being susceptible to stress (Xia et al., 2009), while overexpression of the BR-biosynthetic genes (AtDWF4 and HYDROXYSTEROID DEHYDROGENASE1) in Arabidopsis seedlings result in enhanced tolerance to abiotic stress relative to wild-type seedlings (Divi et al., 2010; Li et al., 2007). Ecotopic expression of AtDWF4 in Brassica napus revealed that $\mathrm{BR}$ mediated growth enhancement and defense responses are likely to be mediated by BES1/BZR1. Further, it was established that BR can simultaneously regulate abiotic stress tolerance and plant productivity (Sahni et al., 2016). In a contradictory study, RNA interference-mediated interruption of the rice SQUALENE SYNTHASE (SQS) catalyzing the initial reaction in the isoprenoid metabolic pathway for sterol (including brassinosteroid) synthesis resulted in reduced stomatal conductance and improved drought tolerance (Manavalan et al., 2012) suggesting that reduced sterol and BR levels might enhance stress tolerance leading to a

TABLE 1 | Major stress responsive genes regulated by Brassinosteroids.

\begin{tabular}{|c|c|c|c|}
\hline Gene & Function & Stress type & Reference \\
\hline$D R E B$ & $\begin{array}{l}\text { Transcription factor that regulates } \\
\text { different cold stress responsive genes }\end{array}$ & Drought stress & $\begin{array}{l}\text { Kagale et al., } 2007 \text {; } \\
\text { Xiao et al., } 2009\end{array}$ \\
\hline $\begin{array}{l}\text { RESPIRATORY BURST OXIDASE } \\
\text { HOMOLOG }(\mathrm{RBOH})\end{array}$ & ROS generation & Photo-oxidative and cold stresses & Xia et al., 2009 \\
\hline $\begin{array}{l}\text { PYRROLINE-5-CARBOXYLATE } \\
\text { SYNTHETASE1 (P5CS1) }\end{array}$ & Proline biosynthesis & Salinity stress & Zeng et al., 2010 \\
\hline DELLA & Gibberellic acid signaling repressor & Submergence stress & Peleg et al., 2011 \\
\hline$S L R 1$ & Gibberellic acid signaling repressor & Submergence stress & Peleg et al., 2011 \\
\hline YODA (YDA) & $\begin{array}{l}\text { Transcription factor that regulate } \\
\text { stomatal conductance }\end{array}$ & Salinity and drought stress & Kim et al., 2012 \\
\hline $\begin{array}{l}\text { ABSCISIC ACID STRESS RIPENING } \\
\text { (ASR) }\end{array}$ & Signal transduction under cold stress & Cold stress & Li B. et al., 2012 \\
\hline LIPOCALINS & Signal transduction under cold stress & Cold stress & Li B. et al., 2012 \\
\hline REMORIN & Membrane skeleton protein & Drought stress & Li B. et al., 2012 \\
\hline MULTIPASS (MPS) & $\begin{array}{l}\text { Transcription factor that regulates cell } \\
\text { size }\end{array}$ & Salinity stress & Schmidt et al., 2013 \\
\hline ALTERNATIVE OXIDASE (AOX) & Protection of plant photosystems & Cold stress & Jiang et al., 2013; Deng et al., 2015 \\
\hline FERRITIN & Iron storage & Salinity & Sharma, 2014 \\
\hline SUPEROXIDE DISMUTASE (SOD) & $\mathrm{H}_{2} \mathrm{O}_{2}$ biosynthesis & Salinity and Pesticide stress & Sharma et al., 2012, 2015 \\
\hline ASCORBATE PEROXIDASE (APX) & ROS scavenging & Salinity and Pesticide Stress & Sharma et al., 2012, 2015 \\
\hline CATALASE (CAT) & ROS scavenging & Salinity and Pesticide Stress & Sharma et al., 2012, 2015 \\
\hline GLUTATHIONE REDUCTASE (GR) & ROS scavenging & Salinity and Pesticide stress & Sharma et al., 2012, 2015 \\
\hline $\begin{array}{l}\text { NON-EXPRESSOR OF } \\
\text { PATHOGENESIS-RELATED GENES1-1 } \\
(\text { NPR1-1) }\end{array}$ & $\begin{array}{l}\text { Transcription factor that regulates } \\
\text { different stress responsive genes }\end{array}$ & Hyper-thermal and Salinity stress & Wei et al., 2015 \\
\hline WRKY & $\begin{array}{l}\text { Transcription factor that regulates } \\
\text { different stress responsive genes }\end{array}$ & Drought stress & Chen et al., 2017 \\
\hline CESTA (CES) & $\begin{array}{l}\text { Transcription factor that regulates } \\
\text { different cold stress responsive genes }\end{array}$ & Cold stress & Eremina et al., 2017 \\
\hline
\end{tabular}


skepticism in acknowledging the role of endogenous BRs in stress tolerance (Jager et al., 2008). Furthermore, rice BR biosynthetic mutant $d 2-1$, exhibited enhanced tolerance to Fe-deficiency and this response could be reversed partially by exogenous BR application. Authors argue that the lower endogenous BRs facilitates $\mathrm{Fe}$ transport and translocation from roots to shoots while complementing the seedlings with BR suppresses the translocation of $\mathrm{Fe}$ from roots to shoots, displaying a severe phenotype of Fe deficiency in shoots (Wang et al., 2015). Nevertheless, the stress response may not be manifested in the form of changes in BR levels but could be reflected in changes in the activity (sensitivity) of BR signaling components as explained by Xia et al. (2009). There are several other important stress regulated genes like CHLORIDE CHANNEL (CLC), transporters and symporters (OsAKT, OsHKT, OsNHX), NON-SELECTIVE CATION CHANNEL (NCC), MYO-INOSITOL SYNTHESIS (PINO1), etc. which play pivotal roles in stress tolerance (Kumar et al., 2013). Further characterization of these genes under the effect of BRs will improve our understanding of their role in BR-mediated stress tolerance.

\section{ROLE OF BRS AT SIGNALING LEVEL}

Research performed in the domain of BR induced stress response and tolerance in the past two decades has provided overwhelming evidence to support the involvement of various key players of BRs signaling in abiotic stress amelioration. One of the remarkable studies conducted by Cui et al. (2012) provide evidence that BR signaling through BRI1 and its quality control is necessary for salt stress tolerance in Arabidopsis. Mutant BRI1 (bri19 and bri1-5) are retained and degraded by the endoplasmic reticulum (ER)-associated protein degradation (ERAD) pathway system. Mutation of $U B C 32$, a functional component of ERAD, is involved in positive regulation of BR signaling pathway through the buildup of the BRI1-9 protein on the plasma membrane. The salt tolerance test conducted on bri1-9 and bri1-9 ubc32 double mutant plants revealed that bri1-9 plants were more saltsensitive relative to wild-type plants while bri1-9 ubc32 double mutants partly rescued the salt-sensitivity of bri1-9. Further, the Arabidopsis BR-insensitive mutant bin2-1 was found to be hypersensitive to salinity stress which was correlated with inhibited induction of stress responsive genes (Zeng et al., 2010). Similar scenarios were observed in rice and Arabidopsis where the combined application of exogenous BRs and salt treatment results in significant up-regulation of transcript and protein level of OsBRI1 and BRI1 as compared to individual treatments of salt or BR, hinting toward a synergistic regulation of the BR receptor at the gene and protein level by salt and exogenously applied BRs (Sharma et al., 2013c; Sharma, 2014). Though these results were in contradiction to the previous studies which show down-regulation in OsBRI1 expression under BR treatment (Yamamuro et al., 2000; Tanabe et al., 2005). This could be due to the difference in the mode of treatment of BRs. In our work (Sharma et al., 2013b) a short-term (8 h) soaking treatment of rice seeds in $10^{-7} \mathrm{M}$ EBL was provided while in the other reports seeds were grown on agar medium containing $10^{-6} \mathrm{M}$ BL for a period of 2 weeks or 10 days suggesting that BR signaling might be differentially modulated by prolonged and short-term exposure to BRs. It has also been shown that prolonged elevated temperature conditions led to increase in root growth mostly independent of auxin, by ubiquitination mediated degradation of BRI1 to down-regulate BRs signaling (Martins et al., 2017). While homologous mutant alleles of BRI1 (bri1-9 and brl3) manifest an increased tolerance to cold stress (Kim et al., 2010), constitutive activation of BR signaling pathways due to gainof-function of an allele of BAK1 in Arabidopsis, elongated-D $($ elg-D) resulted in plants with reduced ability to resist stressful conditions though they displayed improved growth (Chung et al., 2012). Therefore, it is likely that plants might be undergoing a trade-off between growth and stress responses as BR-mediated growth promotion might be occurring due to re-allocation of energy that is normally utilized in defense related pathways. A recent study has shown that BR and autophagy pathway are integrated among each other to coordinate growth and stress response. BIN2 phosphorylates ubiquitin receptor protein DSK2, which targets BES1 for degradation and results in reduced plant growth. On the other hand, accumulation of BES1 in lossof-function $d s k 2$ mutants result in compromised drought and starvation responses (Nolan et al., 2017). Another bridge between BRs signaling and stress acclimation is the process of Regulated Intra-membrane Proteolysis (RIP). RIP controlled by ER stress is a conserved response mechanism in eukaryotes. Various stresses (heat, salinity, inhibition of protein glycosylation) lead to an enhanced translocation of transcription factors (bZIP17 and bZIP28) from the ER through the golgi into the nucleus which activates BR signaling besides activating ER chaperone genes. Under abiotic stress, RIP-dependent ER chaperone synthesis, may promote correct folding or modification of BRI1 which might have undergone impaired maturation and translocation due to stressful conditions. Thus, RIP may enhance BR signaling directly, and promote stress tolerance by enhancing BRI1 localization to the plasma membrane (Che et al., 2010).

In addition to the BR receptors, BR Signaling Kinases (BSKs) are the key components of BR signaling, involved in development and stress signaling in plants. Their BR signaling function is conserved in Arabidopsis and rice. OsBSK3 has been found to be a positive regulator of $\mathrm{BR}$ signaling in rice and directly interacts with OsBRI1, undergoes phosphorylation and transduces the signal to downstream signaling component (Zhang et al., 2016). The transcript level of BSK5 was induced by stimuli like salt, drought, BRs and ABA while the loss of function mutant $b s k 5$ exhibited sensitivity to salinity and ABA. Since, BSKs are known to be positive regulators of BRs signaling, the resulting sensitivity of the bsk5 mutant to stress may be due to repression of BSK5 leading to BR-deficiency that affects salt- and ABA-stress responses (Li Z.Y. et al., 2012). OsGSK1, a GSK3/SHAGGY-like kinase is a homologue of a key component of BR signaling in Arabidopsis, BIN2 (a negative regulator of BRs signaling). OsGSK1 knock-out plants were found to be hypersensitive to BRs and had significantly enhanced tolerance to various abiotic stresses with altered expression of various abiotic stress responsive genes (Koh et al., 2007). 


\section{ROLE OF BRs AT REGULATORY LEVEL}

Brassinosteroids directly or indirectly regulate different stress responsive transcription factors through their signaling module operated through negative regulator BIN2 and key transcription factors (TFs) BZR1/BES1, leading to the activation of stress adaptive signaling pathways (Figure 2). DREB, WRKY, MYB/MYC, GRAS, bZIP, NAC and NPR are the major transcription factors regulating abiotic stress responses in rice. Over expression of DREB in transgenic rice has been found to confer tolerance to salt, drought and cold stress by activating a cascade of genes including RD, ERD and KIN (Chen et al., 2008; Wang et al., 2008). BRs have been known to enhance the expression level of DREB under the normal as well as stressed conditions leading to stress adaptation (Kagale et al., 2007; Xiao et al., 2009). WRKY is another critical component of the complex stress responsive signaling pathways in rice and its expression is found to be induced by BR treatment in plants (Xiao et al., 2009; Chen et al., 2012). OsWRKY08 confers salt, cold and drought tolerance by regulating auxin signaling and stress responsive genes, e.g., RD and COR (Yu et al., 2010; Chen et al., 2012). The OsMYBS3 TF is reported to confer chilling tolerance in rice by regulating DREB/CBF TFs and the cell cycle (Ambawat et al., 2013). MYB/MYC TFs also regulates amino acid metabolism and confers heat tolerance in rice (El-kereamy et al., 2012). Microarray and genome wide expression studies have indicated that expression of this class of TF is regulated by BRs (Goda et al., 2002; Xiao et al., 2009). Recently it is evidenced that the $\mathrm{BR}$ regulated transcription factor CESTA (CES) contributes to the constitutive expression of the transcription factor $\mathrm{CBF}$ that control cold responsive (COR) gene expression. Furthermore, COR genes that are regulated in a CES- and BR- dependent manner but independent to $\mathrm{CBF}$ regulation have also been identified during cold acclimation. It is predicted that BRs induce posttranslational modification of CES and its other redundant TFs which further regulates cold-responsive TFs to induce basal resistance against freezing stress leading to cold acclimation (Eremina et al., 2017). The GRAS domain containing TFs are plant specific playing an array of roles in development and positively regulating the salt, cold and drought stress tolerance in plants (Xu et al., 2015). GRAS TFs are reported to be involved in the BRs signaling pathway (Tong et al., 2009). Over expression of the NAC TFs can improve the salt, cold, drought and heat tolerance of rice (Jeong et al., 2010; Hong et al., 2016). They confer heat and drought stress adaptation by increasing the activity of ROS detoxification enzymes in rice and cold tolerance through the regulation of $C O R$ genes (Fang et al., 2015). Brassinosteroids may regulate NAC TFs during abiotic stress tolerance in crosstalk with other plant growth regulators like ABA (Fujita et al., 2004; Ahammed et al., 2015). RD26 which belongs to the family of NAC TFs, regulates drought-responsive gene expression. A recent study has shown that BES1/BZR1 directly targets and represses the expression of $R D 26$ at a transcription level, while RD26 interacts with BES1 to inhibit its transcriptional activity. Such a mutual inhibitory mechanism not only result in inhibition of BR-induced growth under drought conditions but also prevents the unwanted elicitation of drought response during BR-induced growth (Ye et al., 2017). Also, a NAC TF, JUB1 has been found to regulate $\mathrm{GB} / \mathrm{BR}$ signaling and repress TF PIF4 thereby

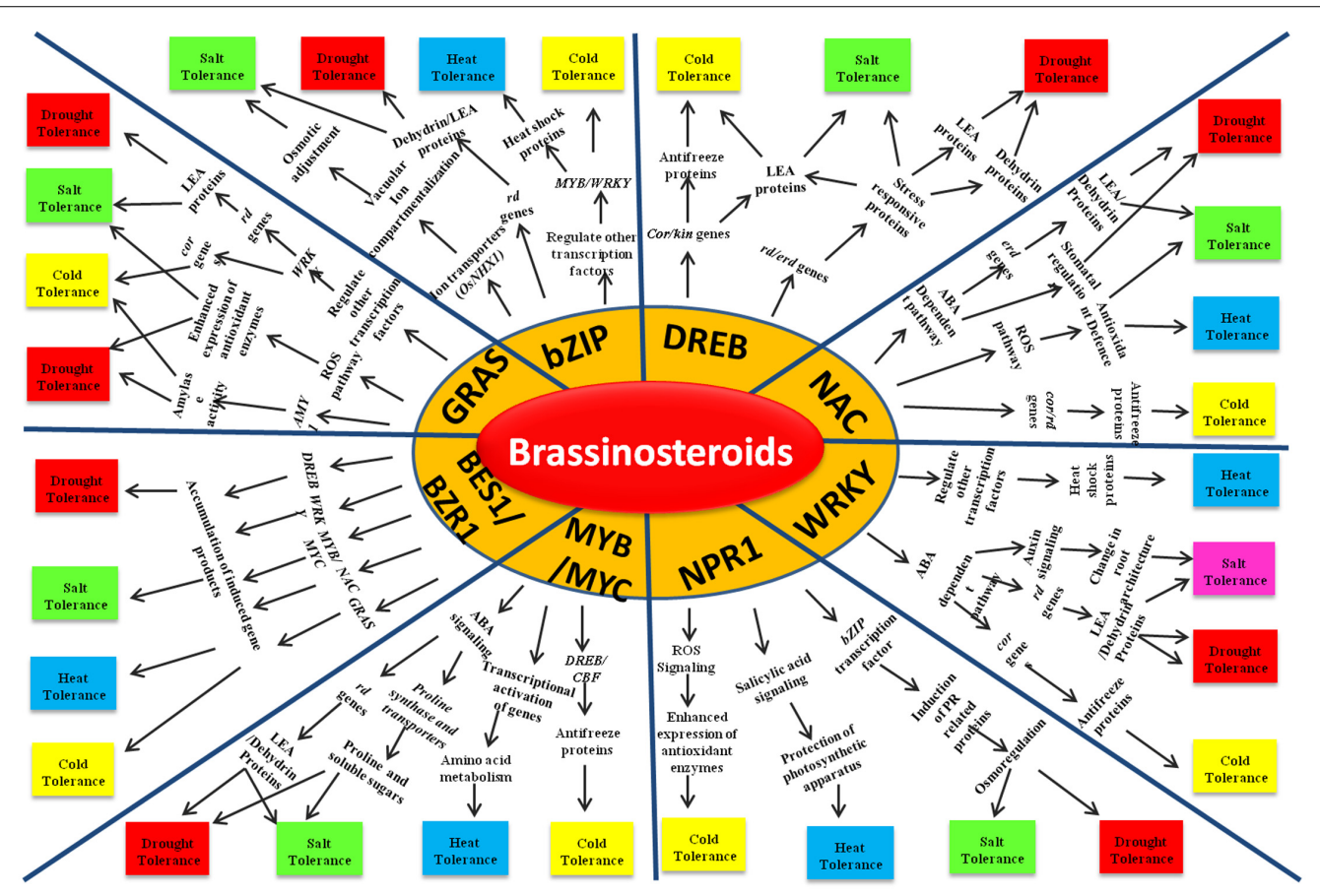

FIGURE 2 | Abiotic stress tolerance in rice by interaction between brassinosteroids and various transcription factors. 


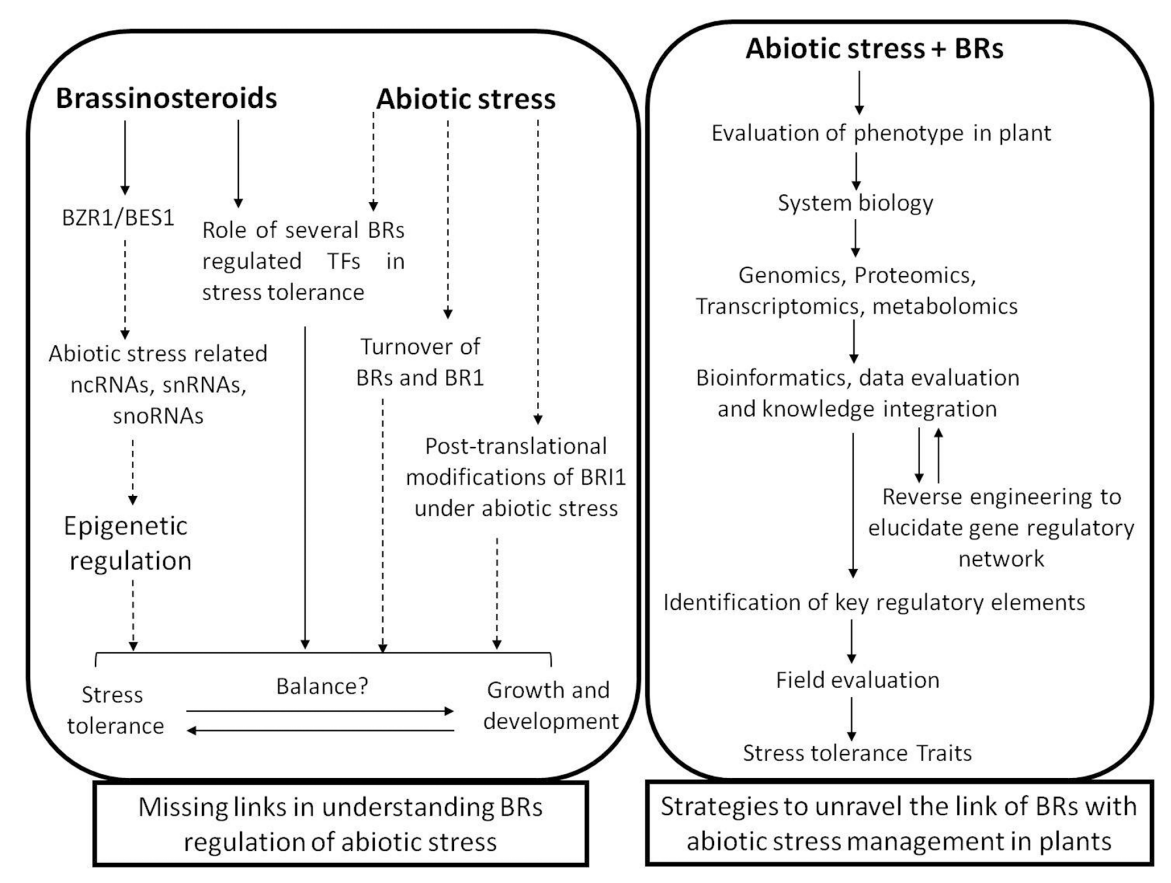

FIGURE 3 | A schematic representation of the missing links in understanding brassinosteroids regulated stress tolerance mechanism and the strategies to address them. Solid lines represent the well-established concepts and dashed lines represent the open questions.

connecting hormonal and environmental stimuli (ShahnejatBushehri et al., 2016). Although, NPR1 is predominantly known for its role in biotic stress response, its role in abiotic stress adaptation is also well explored. NPR1 expression is positively regulated by brassinosteroids that confers abiotic stress tolerance in a salicylic acid mediated pathway (Saini et al., 2015). Overexpression of AtNPR1 gene in rice results in the enhanced expression level of PR proteins and antioxidant enzymes that protects the plants against oxidative stress (Srinivasan et al., 2009). NPR1 also interacts with the TF bZIP and induces the expression of PR proteins which confers salt and drought tolerance in rice through osmoregulation (Akiyama and Pillai, 2001; Srinivasan et al., 2009; Alves et al., 2013). bZIP TFs are one of the largest families of plant TFs and have been found to be indirectly regulated through brassinosteroids in a NPR1 mediated pathway for conferring abiotic stress tolerance in Arabidopsis (Divi et al., 2010; Liu et al., 2014). Overexpression studies with OsbZIP71 has resulted in the enhanced salt- and drought-tolerance in rice through the increased expression of stress responsive genes like NHX1 which is involved in ion compartmentalization and $R D$ genes encoding dehydrins. Its overexpression further enhanced the expression level of OsMYB4 that encodes for a stress responsive TF and regulates abiotic stress responses in rice (Liu T.T. et al., 2013) and are also known to be regulated by BR signaling (Schmidt et al., 2013). As BRs regulate different TFs to confer abiotic stress tolerance in rice, it will be interesting to further explore the pathways to determine how BES1/BZR1 relays signals for the activation of these TFs
Epigenetic regulation has been known to be associated with the expression changes in stress-responsive genes (Luo et al., 2012; Kim et al., 2015). BR regulated BES1 interacts with a pair of histone demethylases and also recruits histone lysine (Wang et al., 2014) suggesting that epigenetic modifications might also regulate the expression of a subset of $\mathrm{BR}$ targeted genes. In rice, H3K36 methyltransferase encoded by SDG725 is important for the methylation of histone lysine residues. Downregulation of SDG725 resulted in various growth defects which were reminiscent of BRs knock-down phenotypes. Transcripts of many BR signaling and synthesis genes (OsDWARF11, BRI1 and $B U 1)$ were reduced more than two-fold upon depletion of SDG725. Furthermore, a depletion of $\mathrm{H} 3 \mathrm{~K} 36 \mathrm{me} 2 / 3$ in chromatin of BR-related genes was observed in $s d g 725$ knock-down plants. Moreover, the SDG725 protein binds directly to BR regulated genes revealing that SDG725-mediated H3K36 methylation is indispensable for the expression of $\mathrm{BR}$ regulated genes to modulate plant growth and development (Sui et al., 2012). Further, genome-wide transcriptome analysis in plants reveals that under abiotic stress conditions large amount of noncoding RNAs (ncRNAs), small nuclear RNAs (snRNAs) and small nucleolar RNAs (snoRNAs) are expressed (Liu T.T. et al., 2013) and possibly they have a role in chromatin regulation, translational repression and regulation of RNA stability during stress response (Di et al., 2014). Hence, it is equally interesting to look at the modulation of these snRNA by BRs and their implication in abiotic stress tolerance.

Recently there has been a huge interest in studying abiotic stress in the context of protein folding, stabilization and 
dynamics (Ortbauer, 2013). The association of BR signaling component (BES1) with Heat shock protein 90 (HSP90) which is a known molecular chaperon and implicated in protein folding, stability, trafficking and degradation provides evidence for an indirect link of possible involvement of BRs mediated protein folding and abiotic stress tolerance (Shigeta et al., 2014). Besides protein conformation, BRs also regulate the other posttranslational modifications of proteins like phosphorylation, ubiquitination and sumoylation which play critical role in abiotic stress tolerance in plants (Kelley and Estelle, 2012; Toit, 2014). Furthermore, the regulation of BR receptors is also believed to be critical for the response of the plant to various stresses. Two important processes that regulate the functioning of $\mathrm{BR}$ receptor are clatharin mediated endocytosis (CME) and phosphorylation of the kinase residues on BRI1 (Clouse, 2011; Martins et al., 2015). CME in association with a network of proteins, including clathrin, adaptors, and accessory proteins are involved in selection and recruitment of cargos which are further fated for recycling or degradation (Di Rubbo et al., 2013). Salinity induced endocytosis has been implicated in adaptation of plants to stresses (Galvan-Ampudia et al., 2013). Though various genetic, biochemical and advanced microscopy studies have led to the establishment of endocytosis as a crucial process that regulates many diverse aspects of plant life but, a knowledge gap exists in integrating CME of BRI1 in response to diverse environmental cues and their implications in stress adaptation. Furthermore, to the best of our knowledge, no study has been conducted so far to examine the changes in the phosphorylation status of the BRI1 receptor complex under the effect of stress. As BAK1 has been found to bind to FLAGELLIN-SENSITIVE 2 (FLS-2) to regulate biotic stress responses (Chinchilla et al., 2007; Lozano-Durán and Belkhadir, 2017), it is quite plausible that BRI1 could also be acting as a co-receptor to specific molecules of salt or some xenobiotics to modulate BR signaling pathway. Such studies could help immensely in deciphering novel mechanisms of BR related stress responses.

\section{FUTURE PROSPECTS AND CONCLUSION}

Conferring abiotic stress tolerance in plants is a fairly complex process, and diverse mechanisms are being explored which are linked to this event. At present, there are many reports

\section{REFERENCES}

Ahammed, G. J., Li, X., Xia, X. J., Shi, K., Zhou, Y. H., and Yu, J. Q. (2015). Enhanced photosynthetic capacity and antioxidant potential mediate brassinosteriod-induced phenanthrene stress tolerance in tomato. Environ. Pollut. 201, 58-66. doi: 10.1016/j.envpol.2015.02.024

Akiyama, T., and Pillai, A. M. (2001). Molecular cloning, characterization and in vitro expression of a novel endo-1, 3-glucanase up-regulated by ABA and drought stress in rice (Oryza sativa L.). Plant Sci. 161, 1089-1098. doi: 10.1016/ S0168-9452(01)00518-0

Alves, M. S., Dadalto, S. P., Gonçalves, A. B., De Souza, G. B., Barros, V. A., and Fietto, L. G. (2013). Plant bZIP transcription factors responsive to pathogens: a review. Int. J. Mol. Sci. 14, 7815-7828. establishing the role of BRs in modulating stress related responses in plants. However, the intricate mechanisms associated with such responses in plants are still elusive (Figure 3). In recent years, there is substantial progress in understanding various components associated with the perception of BR signals and their transduction, yet the interlinking of these signals leading to abiotic stress tolerance in plant is still a subject of great interest. Deeper insights into the actions of BRs at multiple levels and the integration of these inputs will probably provide a roadmap for addressing the problem more holistically. Further, the dynamics of BR homeostasis which is greatly dependent on its synthesis, degradation and transport need to be explored in the context of abiotic stress and other environmental stimuli. It is also of great relevance to understand the interplay of various phytohormones with BR which ultimately broadens its biological functions. The insights into such crosstalk at signaling level needs to be investigated and understanding their modulation by abiotic stress will lead to addition of knowledge in the area. Moreover, with rapid development of genomics and proteomics technologies leading to identification of key genes and proteins related to stress responses in plants provide a suitable platform to explore the role of BR signaling in stress amelioration. Furthermore, addition of knowledge on transcriptional and post-transcriptional as well as translational and post-translational events regulated by BRs will be critical in modulating the regulatory role of BRs in abiotic stress tolerance in plants.

\section{AUTHOR CONTRIBUTIONS}

All authors listed have made a substantial, direct and intellectual contribution to the work, and approved it for publication.

\section{ACKNOWLEDGMENTS}

University Grants Commission (UGC), New Delhi, India is duly acknowledged for financial support. The authors also acknowledge the Department of Biotechnology (Government of India) for Senior Research Fellowship to NK. They also greatly indebted to Dr. Allan Bruce Downie, Department of Horticulture, University of Kentucky, United States for critical editing of the manuscript.

Ambawat, S., Sharma, P., Yadav, N. R., and Yadav, R. C. (2013). MYB transcription factor genes as regulators for plant responses: an overview. Physiol. Mol. Biol. Plants 19, 307-321. doi: 10.1007/s12298-013-0179-1

Ashraf, M., and Harris, P. J. C. (2013). Photosynthesis under stressful environments: an overview. Photosynthetica 51, 163-190. doi: 10.1007/s11099013-0021-6

Bajguz, A. (2009). Brassinosteroid enhanced the level of abscisic acid in Chlorella vulgaris subjected to short-term heat stress. J. Plant Physiol. 166, 882-886. doi: 10.1016/j.jplph.2008.10.004

Bajguz, A. (2011). Suppression of Chlorella vulgaris growth by cadmium, lead, and copper stress and its restoration by endogenous brassinolide. Arch. Environ. Contam. Toxicol. 60, 406-416. doi: 10.1007/s00244-0109551-0 
Barton, N. H., and Turelli, M. (1990). Evolutionary quantitative genetics: How little do we know? Annu. Rev. Genet. 23, 337-370.

Basu, S., and Roychoudhury, A. (2014). Expression profiling of abiotic stressinducible genes in response to multiple stresses in rice (Oryza sativa L.) varieties with contrasting level of stress tolerance. Biomed Res. Int. 2014:706890. doi: 10.1155/2014/706890

Baxter, A., Mittler, R., and Suzuki, N. (2013). ROS as key players in plant stress signalling. J. Exp. Bot. 65, 1229-1240. doi: 10.1093/jxb/ert375

Belkhadir, Y., and Jaillais, Y. (2015). The molecular circuitry of brassinosteroid signaling. New Phytol. 206, 522-540. doi: 10.1111/nph.13269

Bhatnagar-Mathur, P., Valdez, V., and Sharma, K. K. (2008). Transgenic approaches for abiotic stress tolerance in plants: retrospect and prospects. Plant Cell Rep. 27, 411-424. doi: 10.1007/s00299-007-0474-9

Chaiwanon, J., and Wang, Z. Y. (2015). Spatiotemporal brassinosteroid signaling and antagonism with auxin pattern stem cell dynamics in Arabidopsis roots. Curr. Biol. 20, 1031-1042. doi: 10.1016/j.cub.2015.02.046

Che, P., Bussell, J. D., Zhou, W., Estavillo, G. M., Pogson, B. J., and Smith, S. M. (2010). Signaling from the endoplasmic reticulum activates brassinosteroid signaling and promotes acclimation to stress in Arabidopsis. Sci. Signal. 3:ra69. doi: 10.1126/scisignal.2001140

Chen, J., Nolan, T. M., Ye, H., Zhang, M., Tong, H., Xin, P., et al. (2017). Arabidopsis WRKY46, WRKY54, and WRKY70 transcription factors are involved in brassinosteroid-regulated plant growth and drought responses. Plant Cell 29, 1425-1439. doi: 10.1105/tpc.17.00364

Chen, J. Q., Meng, X. P., Zhang, Y., Xia, M., and Wang, X. P. (2008). Overexpression of OsDREB genes lead to enhanced drought tolerance in rice. Biotechnol. Lett. 30, 2191-2198. doi: 10.1007/s10529-008-9811-5

Chen, L., Song, Y., Li, S., Zhang, L., Zhang, L., Zou, C., et al. (2012). The role of WRKY transcription factors in plant abiotic stresses. Biochim. Biophys. Acta 1819, 120-128. doi: 10.1016/j.bbagrm.2011.09.002

Chinchilla, D., Zipfel, C., Robatzek, S., Kemmerling, B., Nürnberger, T., Jones, J. D., et al. (2007). A flagellin-induced complex of the receptor FLS2 and BAK1 initiates plant defence. Nature 448, 497-500. doi: 10.1038/nature05999

Choudhary, S. P., Oral, H. V., Bhardwaj, R., Yu, J. Q., and Tran, L. S. (2012a). Interaction of brassinosteroids and polyamines enhances copper stress tolerance in Raphanus sativus. J. Exp. Bot. 63, 5659-5675. doi: 10.1093/jxb/ ers 219

Choudhary, S. P., Yu, J. Q., Yamaguchi-Shinozaki, K., Shinozaki, K., and Tran, L. S. (2012b). Benefits of brassinosteroid crosstalk. Trends Plant Sci. 17, 594-605. doi: 10.1016/j.tplants.2012.05.012

Chung, Y., Choe, V., Fujioka, S., Takatsuto, S., Han, M., Jeon, J. S., et al. (2012). Constitutive activation of brassinosteroid signaling in the Arabidopsis elongated-D/bak1 mutant. Plant Mol. Biol. 80, 489-501. doi: 10.1007/s11103012-9963-5

Chung, Y., Kwon, S., and Choe, S. (2014). Antagonistic regulation of arabidopsis growth by brassinosteroids and abiotic stresses. Mol. Cells 37, 795-803. doi: $10.14348 /$ molcells.2014.0127

Clouse, S. D. (1996). Molecular genetic studies confirm the role of brassinosteroids in plant growth and development. Plant J. 10, 1-8. doi: 10.1046/j.1365-313X. 1996.10010001.x

Clouse, S. D. (2011). Brassinosteroid signal transduction: from receptor kinase activation to transcriptional networks regulating plant development. Plant Cell 23, 1219-1230. doi: 10.1105/tpc.111.084475

Cui, F., Liu, L., Zhao, Q., Zhang, Z., Li, Q., Lin, B., et al. (2012). Arabidopsis ubiquitin conjugase UBC32 is an ERAD component that functions in brassinosteroid-mediated salt stress tolerance. Plant Cell 24, 233-244. doi: $10.1105 /$ tpc. 111.093062

Cui, J. X., Zhou, Y. H., Ding, J. G., Xia, X. J., Shi, K., Chen, S. C., et al. (2011). Role of nitric oxide in hydrogen peroxide-dependent induction of abiotic stress tolerance by brassinosteroids in cucumber. Plant Cell Environ. 34, 347-358. doi: $10.1111 / j .1365-3040.2010 .02248 . x$

Cui, L., Zou, Z., Zhang, J., Zhao, Y., and Yan, F. (2015). 24-Epibrassinoslide enhances plant tolerance to stress from low temperatures and poor light intensities in tomato (Lycopersicon esculentum Mill.). Funct. Integr. Genomics 16, 29-35. doi: 10.1007/s10142-015-0464-x

Daszkowska-Golec, A., and Szarejko, I. (2013). Open or close the gate - stomata action under the control of phytohormones in drought stress conditions. Front. Plant Sci. 4:138. doi: 10.3389/fpls.2013.00138
Deng, X. G., Zhu, T., Zhang, D. W., and Lin, H. H. (2015). The alternative respiratory pathway is involved in brassinosteroid-induced environmental stress tolerance in Nicotiana benthamiana. J. Exp. Bot. 66, 6219-6232. doi: $10.1093 /$ jxb/erv328

Deng, Z., Zhang, X., Tang, W., Oses-Prieto, J. A., Suzuki, N., Gendron, J. M., et al. (2007). A proteomic study of brassinosteroid response in Arabidopsis. Mol. Cell. Proteomics 6, 2058-2071. doi: 10.1074/mcp.M700123-MCP200

Di, C., Yuan, J., Wu, Y., Li, J., Lin, H., Hu, L., et al. (2014). Characterization of stress-responsive lncRNAs in Arabidopsis thaliana by integrating expression, epigenetic and structural features. Plant J. 80, 848-861. doi: 10.1111/tpj.12679

Di Rubbo, S., Irani, N. G., Kim, S. Y., Xu, Z. Y., Gadeyne, A., Dejonghe, W., et al. (2013). The clathrin adaptor complex AP-2 mediates endocytosis of BRASSINOSTEROID INSENSITIVE1 in Arabidopsis. Plant Cell 25, 2986-2997. doi: $10.1105 /$ tpc. 113.114058

Divi, U. K., and Krishna, P. (2010). "Brassinosteroids confer stress tolerance," in Plant Stress Biology: From Genomics to Systems Biology, ed. H. Hirt (Weinheim: Wiley-VCH Verlag GmbH \& Co. KGaA). doi: 10.1002/9783527628964.ch6

Divi, U. K., Rahman, T., and Krishna, P. (2010). Brassinosteroid-mediated stress tolerance in Arabidopsis shows interactions with abscisic acid, ethylene and salicylic acid pathways. BMC Plant Biol. 10:151. doi: 10.1186/1471-2229-10-151

Divi, U. K., Rahman, T., and Krishna, P. (2016). Gene expression and functional analyses in brassinosteroid-mediated stress tolerance. Plant Biotechnol. J. 14, 419-432. doi: 10.1111/pbi.12396

Duan, J., and Cai, W. (2012). OsLEA3-2, an abiotic stress induced gene of rice plays a key role in salt and drought tolerance. PLOS ONE 7:e45117. doi: 10.1371/ journal.pone.0045117

El-kereamy, A., Bi, Y. B., Ranathunge, K., Beatty, P. H., Good, A. H., and Rothstein, S. J. (2012). The rice R2R3-MYB transcription factor OsMYB55 is involved in the tolerance to high temperature and modulates amino acid metabolism. PLOS ONE 7:e52030. doi: 10.1371/journal.pone.0052030

Eremina, M., Unterholzner, S. J., Rathnayake, A. I., Castellanos, M., Khan, M., Kugler, K. G., et al. (2017). Brassinosteroids participate in the control of basal and acquired freezing tolerance of plants. Proc. Natl. Acad. Sci. U.S.A. 113, E5982-E5991. doi: 10.1073/pnas.1700593114

Fang, Y., Liao, K., Du, H., Xu, Y., Song, H., Li, X., et al. (2015). A stress-responsive NAC transcription factor SNAC3 confers heat and drought tolerance through modulation of reactive oxygen species in rice. J. Exp. Bot. 66, 6803-6817. doi: $10.1093 / \mathrm{jxb} / \mathrm{erv} 386$

FAO (2008). Food and Agricultural Statistics Global Outlook. Available at: http://faostat.fao.org/Portals/documents/pdf/world.pdf

Farooq, M., Wahid, A., Lee, D. J., Cheema, S. A., and Aziz, T. (2010). Comparative time course action of the foliar applied glycinebetaine, salicylic acid, nitrous oxide, brassinosteroids and spermine in improving drought resistance of rice. J. Agron. Crop. Sci. 196, 336-345. doi: 10.1111/j.1439-037X.2010.00422.x

Fu, F. Q., Mao, W. H., Shi, K., Zhou, Y. H., Asami, T., and Yu, J. Q. (2008). A role of brassinosteroids in early fruit development in cucumber. J. Exp. Bot. 59, 2299-2308. doi: 10.1093/jxb/ern093

Fujita, M., Fujita, Y., Maruyama, K., Seki, M., Hiratsu, K., Ohme-Takagi, M., et al. (2004). A dehydration-induced NAC protein, RD26, is involved in a novel ABAdependent stress-signaling pathway. Plant J. 39, 863-876. doi: 10.1111/j.1365313X.2004.02171.X

Galvan-Ampudia, C. S., Julkowska, M. M., Darwish, E., Gandullo, J., Korver, R. A., Brunoud, G., et al. (2013). Halotropism is a response of plant roots to avoid a saline environment. Curr. Biol. 23, 2044-2050. doi: 10.1016/j.cub.2013.08.042

Garg, A. K., Kim, J. K., Owens, T. G., Ranwala, A. P., Choi, Y. D., Kochian, L. V., et al. (2002). Trehalose accumulation in rice plants confers high tolerance levels to different abiotic stresses. Proc. Natl. Acad. Sci. U.S.A. 99, 15898-15903. doi: $10.1073 /$ pnas. 252637799

Goda, H., Shimada, Y., Asami, T., Fujioka, S., and Yoshida, S. (2002). Microarray analysis of brassinosteroid-regulated genes in Arabidopsis. Plant Physiol. 130, 1319-1334. doi: 10.1104/pp.011254

Golldack, D., Li, C., Mohan, H., and Probst, N. (2014). Tolerance to drought and salt stress in plants: unraveling the signaling networks. Front. Plant Sci. 5:151. doi: $10.3389 /$ fpls.2014.00151

González-García, M. P., Vilarrasa-Blasi, J., Zhiponova, M., Divol, F., MoraGarcía, S., Russinova, E., et al. (2011). Brassinosteroids control meristem size by promoting cell cycle progression in Arabidopsis roots. Development 138, 849-859. doi: 10.1242/dev.057331 
Gregorio, G. B., Islam, M. R., Vergara, G. V., and Thirumeni, S. (2013). Recent advances in rice science to design salinity and other abiotic stress tolerant rice varieties. SABRAO J. Breed. Genet. 45, 31-41.

Gregorio, G. B., Senadhira, D., Mendoza, R. D., Manigbas, N. L., Roxas, J. P., et al. (2002) Progress in breeding for salinity tolerance and associated abiotic stresses in rice. Field Crops Res. 76, 91-101.

Gudesblat, G. E., Schneider-Pizoñ, J., Betti, C., Mayerhofer, J., Vanhoutte, I., van, Dongen W, et al. (2012). Speechless integrates brassinosteroid and stomata signalling pathways. Nat. Cell Biol. 14, 548-554. doi: 10.1038/ncb2471

Guerriero, G., Hausman, J. F., and Cai, G. (2014). No Stress! Relax! Mechanisms governing growth and shape in plant cells. Int. J. Mol. Sci. 15, 5094-5114. doi: 10.3390/ijms15035094

Guo, H. Q., Li, L., Ye, H. X., Yu, X., Algreen, A., and Yin, Y. (2009). Three related receptor-like kinases are required for optimal cell elongation in Arabidopsis thaliana. Proc. Natl. Acad. Sci. U.S.A. 106, 7648-7653. doi: 10.1073/pnas. 0812346106

Gururani, M. A., Venkatesh, J. A., and Tran, L. (2015). Regulation of photosynthesis during abiotic stress-induced photoinhibition. Mol. Plant. 8, 1304-1320. doi: 10.1016/j.molp.2015.05.005

Hacham, Y., Holland, N., Butterfield, C., Ubeda-Tomas, S., Bennett, M. J., Chory, J., et al. (2011). Brassinosteroid perception in the epidermis controls root meristem size. Development 138, 839-848. doi: 10.1242/dev.061804

Haubrick, L. L., Torsethaugen, G., and Assmann, S. M. (2006). Effect of brassinolide, alone and in concert with abscisic acid, on control of stomatal aperture and potassium currents of Vicia faba guard cell protoplasts. Physiol. Plant. 128, 134-143. doi: 10.1111/j.1399-3054.2006.00708.x

Hayat, S., Alyemeni, M., and Hasan, S. (2012). Foliar spray of brassinosteroid enhances yield and quality of Solanum lycopersicum under cadmium stress. Saudi J. Biol. Sci. 19, 325-335. doi: 10.1016/j.sjbs.2012.03.005

Hegazi, A. M., El-Shraiy, A. M., and Ghoname, A. A. (2017). Mitigation of salt stress negative effects on sweet pepper using arbuscular mycorrhizal fungi (AMF), Bacillus megaterium and brassinosteroids (BRs). Gesunde Pflanzen 2, 91-102. doi: 10.1007/s10343-017-0393-9

Heyman, J., Kumpf, R. P., and De Veylder, L. (2014). A quiescent path to plant longevity. Trends Cell Biol. 24, 443-448. doi: 10.1016/j.tcb.2014.03.004

Hoffmann, A. A., and Parsons, P. A. (1991). Evolutionary Genetics and Environmental Stress. Oxford: Oxford University Press.

Hong, Y., Zhang, H., Huang, L., Li, D., and Song, F. (2016). Overexpression of a stress-responsive NAC transcription factor gene ONAC022 improves drought and salt tolerance in rice. Front. Plant Sci. 7:4. doi: 10.3389/fpls.2016.00004

$\mathrm{Hu}, \mathrm{H}$., and Xiong, L. (2014). Genetic engineering and breeding of droughtresistant crops. Annu. Rev. Plant Biol. 65, 715-741. doi: 10.1146/annurevarplant-050213-040000

Hu, S., Wang, C., Sanchez, D. L., Lipka, A. E., Liu, P., Yin, Y., et al. (2017). Gibberellins promote brassinosteroids action and both increase heterosis for plant height in maize (Zea mays L.). Front. Plant Sci. 8:1039. doi: 10.3389/fpls. 2017.01039

IRRI (2006). Bringing Hope, Improving Lives: Strategic Plan 2007-2015. Manila: IRRI, 61.

Ismail, A. M., Heuer, S., Thomson, M. J., and Wissuwa, M. (2007). Genetic and genomic approaches to develop rice germplasm for problem soils. Plant Mol. Biol. 65, 547-570. doi: 10.1007/s11103-007-9215-2

Ismail, A. M., and Horie, T. (2017). Genomics, physiology, and molecular breeding approaches for improving salt tolerance. Annu. Rev. Plant Biol. 68, 405-434. doi: 10.1146/annurev-arplant-042916-040936

Jager, C. E., Symons, G. M., Ross, J. J., and Reid, J. B. (2008). Do brassinosteroids mediate the water stress response? Physiol. Plant. 133, 417-425. doi: 10.1111/j. 1399-3054.2008.01057.x

Jeong, J. S., Kim, Y. S., Baek, K. H., Jung, H., Ha, S. H., Do Choi, Y., et al. (2010). Root-specific expression of OsNAC10 improves drought tolerance and grain yield in rice under field drought conditions. Plant Physiol. 153, 185-197. doi: 10.1104/pp.110.154773

Jiang, Y. P., Cheng, F., Zhou, Y. H., Xia, X. J., Mao, W. H., Shi, K., et al. (2012a). Brassinosteroid-induced $\mathrm{CO}_{2}$ assimilation is associated with increased stability of redox-sensitive photosynthetic enzymes in the chloroplasts in cucumber plants. Biochem. Biophys. Res. Commun. 426, 390-394. doi: 10.1016/j.bbrc.2012. 08.100
Jiang, Y. P., Cheng, F., Zhou, Y. H., Xia, X. J., Mao, W. H., Shi, K., et al. (2012b). Cellular glutathione redox homeostasis plays an important role in the brassinosteroid induced increase in $\mathrm{CO}_{2}$ assimilation in Cucumis sativus. New Phytol. 194, 932-943. doi: 10.1111/j.1469-8137.2012.04111.x

Jiang, Y. P., Huang, L. F., Cheng, F., Zhou, Y. H., Xia, X. J., Mao, W. H., et al. (2013). Brassinosteroids accelerate recovery of photosynthetic apparatus from cold stress by balancing the electron partitioning, carboxylation and redox homeostasis in cucumber. Physiol. Plant. 148, 133-145. doi: 10.1111/j.13993054.2012.01696. $\mathrm{x}$

Jin, S. H., Li, X. Q., Wang, G. G., and Zhu, X. T. (2015). Brassinosteroids alleviate high-temperature injury in Ficus concinna seedlings via maintaining higher antioxidant defence and glyoxalase systems. AoB Plants 7:plv009. doi: 10.1093/ aobpla/plv009

Kagale, S., Divi, U. K., Krochko, J. E., Keller, W. A., and Krishna, P. (2007). Brassinosteroid confers tolerance in Arabidopsis thaliana and Brassica napus to a range of abiotic stresses. Planta 225, 353-364. doi: 10.1007/s00425-0060361-6

Kaur, N., Dhawan, M., Sharma, I., and Pati, P. K. (2016a). Interdependency of reactive oxygen species generating and scavenging system in salt sensitive and salt tolerant cultivars of rice. BMC Plant Biol. 16:131. doi: 10.1186/s12870-0160824-2

Kaur, N., Kirat, K., Saini, S., Sharma, I., Gantet, P., and Pati, P. K. (2016b). Reactive oxygen species generating system and brassinosteroids are linked to salt stress adaptation mechanisms in rice. Plant Signal Behav. 11:e1247136. doi: 10.1080/15592324.2016.1247136

Kaur, N., and Pati, P. K. (2017). Integrating classical with emerging concepts for better understanding of salinity stress tolerance mechanisms in rice. Front. Environ. Sci. 5:42. doi: 10.3389/fenvs.2017.00042

Kauschmann, A., Jessop, A., Koncz, C., Szekeres, M., Willmitzer, L., and Altmann, T. (1996). Genetic evidence for an essential role of brassinosteroids in plant development. Plant J. 9, 701-713. doi: 10.1046/j.1365-313X.1996. 9050701.x

Kelley, D. R., and Estelle, M. (2012). Ubiquitin-mediated control of plant hormone signaling. Plant Physiol. 160, 47-55. doi: 10.1104/pp.112.200527

Khong, G., Richaud, F., Coudert, Y., Pati, P. K., Santi, C., Périn, C., et al. (2008). Modulating rice stress tolerance by transcription factors. Biotechnol. Genet. Eng. Rev. 25, 381-404. doi: 10.5661/bger-25-381

Kim, J. M., Sasaki, T., Ueda, M., Sako, K., and Seki, M. (2015). Chromatin changes in response to drought, salinity, heat, and cold stresses in plants. Front. Plant Sci. 2:114. doi: 10.3389/fpls.2015.00114

Kim, S. Y., Kim, B. H., Lim, C. J., Lim, C. O., and Nam, K. H. (2010). Constitutive activation of stress-inducible genes in a brassinosteroid-insensitive 1 (bri1) mutant results in higher tolerance to cold. Physiol. Plant. 138, 191-204. doi: 10.1111/j.1399-3054.2009.01304.x

Kim, T. W., Michniewicz, M., Bergmann, D. C., and Wang, Z. Y. (2012). Brassinosteroid regulates stomatal development by GSK3-mediated inhibition of a MAPK pathway. Nature 482, 419-422. doi: 10.1038/nature10794

Kitsios, G., and Doonan, J. H. (2011). Cyclin dependent protein kinases and stress responses in plants. Plant Signal. Behav. 6, 204-209. doi: 10.4161/psb.6.2. 14835

Koh, S., Lee, S. C., Kim, M. K., Koh, J. H., Lee, S., An, G., et al. (2007). T-DNA tagged knockout mutation of rice OsGSK1, an orthologue of Arabidopsis BIN2, with enhanced tolerance to various abiotic stresses. Plant Mol. Biol. 65, 453-466. doi: 10.1007/s11103-007-9213-4

Kumar, K., Kumar, M., Kim, S. R., Ryu, H., and Cho, Y. G. (2013). Insights into genomics of salt stress response in rice. Rice 6:27. doi: 10.1186/19398433-6-27

Kurepin, L. V., Qaderi, M. M., Back, T. G., Reid, D. M., and Pharis, R. P. (2008). A rapid effect of applied brassinolide on abscisic acid concentrations in Brassica napus leaf tissue subjected to short-term heat stress. Plant Growth Regul. 55, 165-167. doi: 10.1007/s10725-008-9276-5

Lang, Y. Z., Zhang, Z. J., Gu, X. Y., Yang, J. C., and Zhu, Q. S. (2004). A physiological and ecological effect of crimpy leaf character in rice (Oryza sativa L.) II. Photosynthetic character, dry mass production and yield forming. Acta Agron. Sin. 30, 883-887.

Li, B., Zhang, C., Cao, B., Qin, G., Wang, W., and Tian, S. (2012). Brassinolide enhances cold stress tolerance of fruit by regulating plasma membrane 
proteins and lipids. Amino Acids 43, 2469-2480. doi: 10.1007/s00726-0121327-6

Li, F., Asami, T., Wu, X., Tsang, E. W., and Cutler, A. J. (2007). A putative hydroxysteroid dehydrogenase involved in regulating plant growth and development. Plant Physiol. 145, 87-97. doi: 10.1104/pp.107.100560

Li, H., Jiang, L., Youn, J. H., Sun, W., Cheng, Z., Jin, T., et al. (2013). A comprehensive genetic study reveals a crucial role of CYP90D2/D2 in regulating plant architecture in rice (Oryza sativa). New Phytol. 4, 1076-1088. doi: $10.1111 / \mathrm{nph} .12427$

Li, L., Yu, X., Thompson, A., Guo, M., Yoshida, S., Asami, T., et al. (2009). Arabidopsis MYB30 is a direct target of BES1 and cooperates with BES1 to regulate brassinosteroid-induced gene expression. Plant J. 58, 275-286. doi: 10.1111/j.1365-313X.2008.03778.x

Li, Z. Y., Xu, Z. S., He, G. Y., Yang, G. X., Chen, M., Li, L. C., et al. (2012). Mutation in Arabidopsis BSK5 encoding a brassinosteroid-signaling kinase protein affects responses to salinity and abscisic acid. Biochem. Biophys. Res. Commun. 4, 522-527. doi: 10.1016/j.bbrc.2012.08.118

Liu, A. L., Zou, J., Liu, C. F., Zhou, X. Y., Zhang, X. W., Luo, G. Y., et al. (2013). Overexpression of OsHsfA7 enhanced salt and drought tolerance in transgenic rice. Mol. Biol. Rep. 46, 31-36.

Liu, C., Mao, B., Ou, S., Wang, W., Liu, L., Wu, Y., et al. (2014). OsbZIP71, a bZIP transcription factor, confers salinity and drought tolerance in rice. Plant Mol. Biol. 84, 19-36. doi: 10.1007/s11103-013-0115-3

Liu, J., Zhang, D., Sun, X., Ding, T., Lei, B., and Zhang, C. (2017). Structure-activity relationship of brassinosteroids and their agricultural practical usages. Steroids 124, 1-17. doi: 10.1016/j.steroids.2017.05.005

Liu, T. T., Zhu, D., Chen, W., Deng, W., He, H., He, G., et al. (2013). A global identification and analysis of small nucleolar RNAs and possible intermediatesized non-coding RNAs in Oryza sativa. Mol. Plant. 6, 830-846. doi: 10.1093/ $\mathrm{mp} / \mathrm{sss} 087$

Liu, X. M., Kim, K. E., Kim, K. C., Nguyen, X. C., Han, H. J., Jung, M. S., et al. (2010). Cadmium activates Arabidopsis MPK3 and MPK6 via accumulation of reactive oxygen species. Phytochemistry 71, 614-618. doi: 10.1016/j.phytochem. 2010.01.005

Liu, Y., Zhao, Z., Si, J., Di, C., Han, J., and An, L. (2009). Brassinosteroids alleviate chilling induced oxidative damage by enhancing antioxidant defense system in suspension cultured cells of Chorispora bungeana. Plant Growth Regul. 59, 207-214. doi: 10.1007/s10725-009-9405-9

Lobréaux, S., Thoiron, S., and Briat, J. F. (1995). Induction of ferritin synthesis in maize leaves by an iron-mediated oxidative stress. Plant J. 8, 443-449. doi: 10.1046/j.1365-313X.1995.08030443.x

Louis Setter, T., and Vidonia Laureles, E. (1996). The beneficial effect of reduced stem elongation growth on submergence tolerance of rice. J. Exp. Bot. 47, 1551-1559. doi: 10.1093/jxb/47.10.1551

Lozano-Durán, R., and Belkhadir, Y. (2017). A technical framework for studying the signaling nexus of brassinosteroids and immunity. Methods Mol. Biol. 1564, 49-61. doi: 10.1007/978-1-4939-6813-8_6

Luo, M., Liu, X., Singh, P., Cui, Y., Zimmerli, L., and Wu, K. (2012). Chromatin modifications and remodeling in plant abiotic stress responses. Biochim. Biophys. Acta 1819, 129-136. doi: 10.1016/j.bbagrm.2011.06.008

Manavalan, L. P., Chen, X., Clarke, J., Salmeron, J., and Nguyen, H. T. (2012). RNAi-mediated disruption of squalene synthase improves drought tolerance and yield in rice. J. Exp. Bot. 63, 163-175. doi: 10.1093/jxb/err258

Marakli, S., and Gozukirmizi, N. (2016). "Abiotic stress alleviation with brassinosteroids in plant roots," in Abiotic and Biotic Stress in Plants - Recent Advances and Future Perspectives, eds A. Shanker and C. Shanker (Rijeka: InTech). doi: 10.5772/61336

Martins, S., Dohmann, E., Dompierre, J., Fischer, W., Pojer, F., Jaillais, Y., et al. (2015). Dual role for ubiquitin in plant steroid hormone receptor endocytosis. Nat. Commun. 6:6151. doi: 10.1038/ncomms7151

Martins, S., Montiel-Jorda, A., Cayrel, A., Huguet, S., Paysant-Le Roux, C., Ljung, K., et al. (2017). Brassinosteroid signaling-dependent root responses to prolonged elevated ambient temperature. Nat. Commun. 8:309. doi: 10.1038/ s41467-017-00355-4

Maruyama, K., Urano, K., Yoshiwara, K., Morishita, Y., Sakurai, N., Suzuki, H., et al. (2014). Integrated analysis of the effects of cold and dehydration on rice metabolites, phytohormones and gene transcripts. Plant Physiol. 164, 1759-1771. doi: 10.1104/pp.113.231720
Mickelbart, M. V., Hasegawa, P. M., and Bailey-Serres, J. (2015). Genetic mechanisms of abiotic stress tolerance that translate to crop yield stability. Nat. Rev. Genet. 16, 237-251. doi: 10.1038/nrg3901

Mizoi, J., and Yamaguchi-Shinozaki, K. (2013). Molecular approaches to improve rice abiotic stress tolerance. Methods Mol. Biol. 956, 269-283. doi: 10.1007/9781-62703-194-3_20

Nakamura, A., Tochio, N., Fujioka, S., Ito, S., Kigawa, T., Shimada, Y., et al. (2017). Molecular actions of two synthetic brassinosteroids, iso-carbaBL and 6deoxoBL, which cause altered physiological activities between Arabidopsis and rice. PLOS ONE 12:e0174015. doi: 10.1371/journal.pone.0174015

Neumann, P. M. (2008). Coping mechanisms for crop plants in drought-prone environments. Ann. Bot. 101, 901-907. doi: 10.1093/aob/mcn018

Ni, J., Shen, Y., Zhang, Y., and Wu, P. (2014). Definition and stabilisation of the quiescent centre in rice roots. Plant Biol. 16, 1014-1019. doi: 10.1111/plb.12138

Nie, W. F., Wang, M. M., Xia, X. J., Zhou, Y. H., Shi, K., Chen, Z., et al. (2013). Silencing of tomato RBOH1 and MPK2 abolishes brassinosteroidinduced H2O2 generation and stress tolerance. Plant Cell Environ. 36, 789-803. doi: 10.1111 /pce. 12014

Noguchi, T., Fujioka, S., Choe, S., Takatsuto, S., Yoshida, S., Yuan, H., et al. (1999). Brassinosteroid-insensitive dwarf mutants of arabidopsis accumulate brassinosteroids. Plant Physiol. 121, 743-752. doi: 10.1104/pp.121. 3.743

Nolan, T. M., Brennan, B., Yang, M., Chen, J., Zhang, M., Li, Z., et al. (2017). Selective autophagy of BES1 mediated by DSK2 balances plant growth and survival. Dev. Cell. 41, 33-46. doi: 10.1016/j.devcel.2017.03.013

Ogawa, D., Abe, K., Miyao, A., Kojima, M., Sakakibara, H., Mizutani, M., et al. (2011). RSS1 regulates the cell cycle and maintains meristematic activity under stress conditions in rice. Nat. Commun. 2:278. doi: 10.1038/ncomms 1279

Oh, M. H., Wu, X., Clouse, S. D., and Huber, S. C. (2011). Functional importance of BAK1 tyrosine phosphorylation in vivo. Plant Signal. Behav. 6, 400-405. doi: $10.4161 /$ psb.6.3.14337

Ortbauer, M. (2013). "Abiotic stress adaptation: protein folding stability and dynamics," in Abiotic Stress -Plant Responses and Applications in Agriculture, eds K. Vahdati and C. Leslie (Rijeka: InTech).

Parry, M. A. J., Flexas, J., and Medrano, H. (2005). Prospects for crop production under drought: research priorities and future directions. Ann. Appl. Biol. 147, 211-226. doi: 10.1111/j.1744-7348.2005.00032.x

Peleg, Z., and Blumwald, E. (2011). Hormone balance and abiotic stress tolerance in crop plants. Curr. Opin. Plant Biol. 14, 290-295. doi: 10.1016/j.pbi.2011.02.001

Peleg, Z., Reguera, M., Tumimbang, E., Walia, H., and Blumwald, E. (2011). Cytokinin-mediated source/sink modifications improve drought tolerance and increase grain yield in rice under water-stress. Plant Biotechnol. J. 9, 747-758. doi: 10.1111/j.1467-7652.2010.00584.x

Peres, A., Churchman, M. L., Hariharan, S., Himanen, K., Verkest, A., Vandepoele, K., et al. (2007). Novel plant-specific cyclin-dependent kinase inhibitors induced by biotic and abiotic stresses. J. Biol. Chem. 282, 25588-25596. doi: 10.1074/jbc.M703326200

Qian, D., Tian, L., and Qu, L. (2015). Proteomic analysis of endoplasmic reticulum stress responses in rice seeds. Sci. Rep. 23:14255. doi: 10.1038/srep14255

Qu, T., Liu, R., Wang, W., An, L., Chen, T., Liu, G., et al. (2011). Brassinosteroids regulate pectin methylesterase activity and AtPME41 expression in Arabidopsis under chilling stress. Cryobiology 63, 111-117. doi: 10.1016/j.cryobiol.2011.07. 003

Rodríguez, M., González, M. C., Cristo, E., Oliva, O., Pujol, M., and BorrasHidalgo, O. (2013). Identification of genes with altered expression levels in contrasting rice cultivars exposed to salt stress treatments. Biotecnol. Apl. 30, $178-181$.

Saad, N. Y., Stamatopoulou, V., Brayé, M., Drainas, D., Stathopoulos, C., and Becker, H. D. (2013). Two-codon T-box riboswitch binding two tRNAs. Proc. Natl. Acad. Sci. U.S.A. 110, 12756-12761. doi: 10.1073/pnas.1304307110

Sahni, S., Prasad, B. D., Liu, Q., Grbic, V., Sharpe, A., Singh, S. P., et al. (2016). Overexpression of the brassinosteroid biosynthetic gene DWF4 in Brassica napus simultaneously increases seed yield and stress tolerance. Sci. Rep. 6:28298. doi: $10.1038 /$ srep 28298

Saini, S., Sharma, I., Kaur, N., and Pati, P. K. (2013). Auxin: a master regulator in plant root development. Plant Cell Rep. 32, 741-757. doi: 10.1007/s00299-0131430-5 
Saini, S., Sharma, I., and Pati, P. K. (2015). Versatile roles of brassinosteroid in plants in the context of its homoeostasis, signaling and crosstalks. Front. Plant Sci. 6:950. doi: 10.3389/fpls.2015.00950

Salas-Fernandez, M. G., Becraft, P. W., Yin, Y. H., and Lübberstedt, T. (2009). From dwarves to giants? Plant height manipulation for biomass yield. Trends Plant Sci. 14, 454-461. doi: 10.1016/j.tplants.2009.06.005

Schmidt, R., Schippers, J. H., Mieulet, D., Obata, T., Fernie, A. R., Guiderdoni, E., et al. (2013). MULTIPASS, a rice R2R3-type MYB transcription factor, regulates adaptive growth by integrating multiple hormonal pathways. Plant J. 76, 258-273. doi: $10.1111 /$ tpj. 12286

Schmitz, A. J., Folsom, J. J., Jikamaru, Y., Ronald, P., and Walia, H. (2013). SUB1A-mediated submergence tolerance response in rice involves differential regulation of the brassinosteroid pathway. New Phytol. 198, 1060-1070. doi: $10.1111 /$ nph. 12202

Seo, Y. S., Chern, M., Bartley, L. E., Han, M., Jung, K. H., Lee, I., et al. (2011). Towards establishment of a rice stress response interactome. PLOS Genet. 7:e1002020. doi: 10.1371/journal.pgen.1002020

Shahnejat-Bushehri, S., Tarkowska, D., Sakuraba, Y., and Balazadeh, S. (2016). Arabidopsis NAC transcription factor JUB1regulates GA/BR metabolism and signaling. Nat. Plants 2:16013. doi: 10.1038/nplants.2016.13

Sharma, I. (2014). Studies on Brassinosteroid Mediated Responses in Oryza sativa L. Under Pesticide and Salt Stress Employing Molecular and Biochemical Approaches. Doctoral Dissertation, Guru Nanak Dev University, Amritsar.

Sharma, I., Bhardwaj, R., and Pati, P. K. (2012). Mitigation of adverse effects of chlorpyrifos by 24-epibrassinolide and analysis of stress markers in a rice variety Pusa Basmati-1. Ecotoxicol. Environ. Saf. 85, 72-81. doi: 10.1016/j.ecoenv.2012. 07.003

Sharma, I., Bhardwaj, R., and Pati, P. K. (2013a). Stress modulation response of 24epibrassinolide against imidacloprid in an elite indica rice variety Pusa Basmati1. Pest Biochem. Physiol. 105, 144-153. doi: 10.1016/j.pestbp.2013.01.004

Sharma, I., Bhardwaj, R., and Pati, P. K. (2015). Exogenous application of 28Homobrassinolide modulates the dynamics of salt and pesticides induced stress responses in an elite rice variety Pusa Basmati-1. J. Plant Growth Regul. 34, 509-518. doi: 10.1007/s00344-015-9486-9

Sharma, I., Ching, E., Saini, S., Bhardwaj, R., and Pati, P. K. (2013b). Exogenous application of brassinosteroid offers tolerance to salinity by altering stress responses in rice variety Pusa Basmati-1. Plant Physiol. Biochem. 69, 17-26. doi: 10.1016/j.plaphy.2013.04.013

Sharma, I., Kaur, N., Saini, S., and Pati, P. K. (2013c). "Emerging dynamics of brassinosteroids research," in Biotechnology: Prospects and Applications, eds R. K. Salar, S. K. Gahlawat, P. Siwach, and J. S. Duhan (New Delhi: Springer), 3-17.

Shi, C., Qi, C., Ren, H., Huang, A., Hei, S., and She, X. (2015). Ethylene mediates brassinosteroid-induced stomatal closure via $\mathrm{G} \alpha$ protein-activated hydrogen peroxide and nitric oxide production in Arabidopsis. Plant J. 82, 280-301. doi: $10.1111 /$ tpj.12815

Shigeta, T., Zaizen, Y., Asami, T., Yoshida, S., Nakamura, Y., Okamoto, S., et al. (2014). Molecular evidence of the involvement of heat shock protein 90 in brassinosteroid signaling in Arabidopsis T87 cultured cells. Plant Cell Rep. 33, 499-510. doi: 10.1007/s00299-013-1550-y

Shigeta, T., Zaizen, Y., Sugimoto, Y., Nakamura, Y., Matsuo, T., and Okamoto, S. (2015). Heat shock protein 90 acts in brassinosteroid signaling through interaction with BES1/BZR1 transcription factor. J. Plant Physiol. 178, 69-73. doi: 10.1016/j.jplph.2015.02.003

Singh, A. P., and Savaldi-Goldstein, S. (2015). Growth control: brassinosteroid activity gets context. J. Exp. Bot. 66, 1123-1132. doi: 10.1093/jxb/erv026

Skirycz, A., Claeys, H., De, Bodt S, Oikawa, A., Shinoda, S., Andriankaja, M., et al. (2011). Pause-and-stop: the effects of osmotic stress on cell proliferation during early leaf development in Arabidopsis and a role for ethylene signaling in cell cycle arrest. Plant Cell 23, 1876-1888. doi: 10.1105/tpc.111. 084160

Srinivasan, T. K., Kumar, R. R., and Kirti, P. B. (2009). Heterologous expression of Arabidopsis NPR1(AtNPR1) enhances oxidative stress tolerance in transgenic tobacco plants. Biotechnol. Lett. 31, 1343-1351. doi: 10.1007/s10529-0090022-5

Sui, P., Jin, J., Ye, S., Mu, C., Gao, J., Feng, H., et al. (2012). H3K36 methylation is critical for brassinosteroid- regulated plant growth and development in rice. Plant J. 70, 340-347. doi: 10.1111/j.1365-313X.2011.04873.x
Sun, S., Chen, D., Li, X., Qiao, S., Shi, C., Li, C., et al. (2015). Brassinosteroid signaling regulates leaf erectness in Oryza sativa via the control of a specific U-type cyclin and cell proliferation. Dev. Cell 34, 220-228. doi: 10.1016/j.devcel. 2015.05.019

Sun, Y., Fan, X. Y., Cao, D. M., Tang, W., He, K., Zhu, J. Y., et al. (2010). Integration of brassinosteroid signal transduction with the transcription network for plant growth regulation in Arabidopsis. Dev. Cell 19, 765-777. doi: 10.1016/j.devcel. 2010.10.010

Szabados, L., and Savoure, A. (2010). Proline: a multifunctional amino acid. Trends Plant Sci. 15, 89-97. doi: 10.1016/j.tplants.2009.11.009

Szekely, G., Abraham, E., and Cseplo, A. (2008). Duplicated P5CS genes of Arabidopsis play distinct roles in stress regulation and developmental control of proline biosynthesis. Plant J. 53, 11-28. doi: 10.1111/j.1365-313X.2007.03318.x

Tanabe, S., Ashikari, M., Fujioka, S., Takatsuto, S., Yoshida, S., Yano, M., et al. (2005). A novel cytochrome P450 is implicated in brassinosteroid biosynthesis via the characterization of a rice dwarf mutant, dwarf11, with reduced seed length. Plant Cell 17, 776-790. doi: 10.1105/tpc.104.024950

Tiwari, S., Lata, C., Singh Chauhan, P., Prasad, V., and Prasad, M. (2017). A functional genomic perspective on drought signalling and its crosstalk with phytohormone-mediated signalling pathways in plants. Curr. Genomics 18, 469-482. doi: 10.2174/1389202918666170605083319

Todaka, D., Shinozaki, K., and Yamaguchi-Shinozaki, K. (2015). Recent advances in the dissection of drought-stress regulatory networks and strategies for development of drought-tolerant transgenic rice plants. Front. Plant Sci. 6:84. doi: $10.3389 /$ fpls.2015.00084

Toit, A. D. (2014). SUMOylation mediates brassinosteroid effects. Nat. Rev. Mol. Cell Biol. 15:632. doi: 10.1038/nrm3879

Tong, H., Jin, Y., Liu, W., Li, F., Fang, J., Yin, Y., et al. (2009). Dwarf and low-tillering, a new member of theGRAS family, plays positive roles in brassinosteroid signaling in rice. Plant J. 58, 803-816. doi: $10.1111 / \mathrm{j} .1365-313 \mathrm{X}$. 2009.03825.x

Uozu, S., Tanaka-Ueguchi, M., Kitano, H., Hattori, K., and Matsuoka, M. (2000). Characterization of XET-related genes of rice. Plant Physiol. 122, 853-859. doi: 10.1104/pp.122.3.853

Vardhini, B. V. (2016). "Enhancement of vegetables and fruits growth and yield by application of brassinosteroids under abiotic stresses," in Plant-Environment Interaction: Responses and Approaches to Mitigate Stress, eds M. M. Azooz and P. Ahmad (New York, NY: John Wiley \& Sons). doi: 10.1002/978111908 1005.ch7

Vert, G., Walcher, C. L., Chory, J., and Nemhauser, J. L. (2008). Integration of auxin and brassinosteroid pathways by Auxin Response Factor 2. Proc. Natl. Acad. Sci. U.S.A. 105, 9829-9834. doi: 10.1073/pnas.0803996105

Vilarrasa-Blasi, J., González-García, M. P., Frigola, D., Fàbregas, N., Alexiou, K. G., López-Bigas, N., et al. (2014). Regulation of plant stem cell quiescence by a brassinosteroid signaling module. Dev. Cell 30, 36-47. doi: 10.1016/j.devcel. 2014.05.020

Vragović, K., Sela, A., Friedlander-Shani, L., Fridman, Y., Hacham, Y., Holland, N., et al. (2015). Translatome analyses capture of opposing tissuespecific brassinosteroid signals orchestrating root meristem differentiation. Proc. Natl. Acad. Sci. U.S.A. 112, 923-928. doi: 10.1073/pnas.1417 947112

Vriet, C., Russinova, E., and Reuzeau, C. (2012). Boosting crop yields with plant steroids. Plant Cell 24, 842-857. doi: 10.1105/tpc.111.094912

Wang, B., Li, G., and Zhang, W. H. (2015). Brassinosteroids are involved in Fe homeostasis in rice (Oryza sativa L.). J. Exp. Bot. 66, 2749-2761. doi: 10.1093/ jxb/erv079

Wang, Q., Guan, Y., Wu, Y., Chen, H., Chen, F., and Chu, C. (2008). Overexpression of a rice OsDREB1F gene increases salt, drought, and low temperature tolerance in both Arabidopsis and rice. Plant Mol. Biol. 67, 589-602. doi: 10.1007/s11103-008-9340-6

Wang, X., Chen, J., Xie, Z., Liu, S., Nolan, T., Ye, H., et al. (2014). Histone lysine methyltransferase SDG8 is involved in brassinosteroid-regulated gene expression in Arabidopsis thaliana. Mol. Plant. 7, 1303-1315. doi: 10.1093/mp/ ssu056

Wang, X., Teng, Y., Zhang, N., Christie, P., Li, Z., Luo, Y., et al. (2017). Rhizobial symbiosis alleviates polychlorinated biphenyls-induced systematic oxidative stress via brassinosteroids signaling in alfalfa. Sci. Total Environ. 592, 68-77. doi: 10.1016/j.scitotenv.2017.03.066 
Wang, Y., and Li, J. (2005). The plant architecture of rice (Oryza sativa). Plant Mol. Biol. 59, 75-84. doi: 10.1007/s11103-004-4038-x

Wani, S. H., Kumar, V., Shriram, V., and Sah, S. K. (2016). Phytohormones and their metabolic engineering for abiotic stress tolerance in crop plants. Crop J. 4, 162-176. doi: 10.1016/j.cj.2016.01.010

Wani, S. H., and Sah, S. K. (2014). Biotechnology and abiotic stress tolerance in rice. Rice Res. 2:e105. doi: 10.4172/jrr.1000e105

Wei, L., Deng, X. G., Zhu, T., Zheng, T., Li, P. X., Wu, J. Q., et al. (2015). Ethylene is involved in brassinosteroids induced alternative respiratory pathway in cucumber (Cucumis sativus L.) seedlings response to abiotic stress. Front. Plant Sci. 6:982. doi: 10.3389/fpls.2015.00982

Wei, Z., and Li, J. (2016). Brassinosteroids regulate root growth, development and symbiosis. Mol. Plant. 4, 86-100. doi: 10.1016/j.molp.2015.12.003

Wolf, S., Mravec, J., Greiner, S., Mouille, G., and Höfte, H. (2012). Plant cell wall homeostasis is mediated by brassinosteroid feedback signaling. Curr. Biol. 22, 1732-1737. doi: 10.1016/j.cub.2012.07.036

Wolf, S., van der Does, D., Ladwig, F., Sticht, C., Kolbeck, A., Schürholz, A. K., et al. (2014). A receptor-like protein mediates the response to pectin modification by activating brassinosteroid signaling. Proc. Natl. Acad. Sci. U.S.A. 111, 1526115266. doi: $10.1073 /$ pnas. 1322979111

Xia, X. J., Chen, Z., and Yum, J. Q. (2010). ROS mediate brassinosteroids-induced plant stress responses. Plant Signal. Behav. 5, 532-534. doi: 10.4161/psb.10989

Xia, X. J., Gao, C. J., Song, L. X., Zhou, Y. H., Shi, K., and Yu, J. Q. (2014). Role of $\mathrm{H}_{2} \mathrm{O}_{2}$ dynamics in brassinosteroid- induced stomatal closure and opening in Solanum lycopersicum. Plant Cell Environ. 37, 2036-2050. doi: 10.1111/pce. 12275

Xia, X. J., Huang, Y. Y., Wang, L., Huang, L. F., Yu, Y. L., Zhou, Y. H., et al. (2006). Pesticides-induced depression of photosynthesis was alleviated by $24-$ epibrassinolide pre-treatment in Cucumis sativus L. Pest Biochem. Physiol. 86, 42-48. doi: 10.1016/j.pestbp.2006.01.005

Xia, X. J., Wang, Y. J., Zhou, Y. H., Tao, Y., Mao, W. H., Shi, K., et al. (2009). Reactive oxygen species are involved in brassinosteroid-induced stress tolerance in cucumber. Plant Physiol. 150, 801-814. doi: 10.1104/pp.109.138230

Xia, X. J., Zhou, Y. H., Ding, J., Shi, K., Asami, T., Chen, Z., et al. (2011). Induction of systemic stress tolerance by brassinosteroid in Cucumis sativus. New Phytol. 191, 706-720. doi: 10.1111/j.1469-8137.2011.03745.x

Xiao, B. Z., Chen, X., Xiang, C. B., Tang, N., Zhang, Q. F., and Xiong, L. Z. (2009). Evaluation of seven function-known candidate genes for their effects on improving drought resistance of transgenic rice under field conditions. Mol. Plant. 2, 73-83. doi: $10.1093 / \mathrm{mp} / \mathrm{ssn} 068$

Xie, L., Yang, C., and Wang, X. (2011). Brassinosteroids can regulate cellulose biosynthesis by controlling the expression of CESA genes in Arabidopsis. J. Exp. Bot. 62, 4495-4506. doi: 10.1093/jxb/err164

Xu, K., Chen, S., Li, T., Ma, X., Liang, X., Ding, X., et al. (2015). OsGRAS23, a rice GRAS transcription factor gene, is involved in drought stress response through regulating expression of stress-responsive genes. BMC Plant Biol. 15:141. doi: 10.1186/s12870-015-0532-3

Yamada, M., Morishita, H., Urano, K., Shiozaki, N., Yamaguchi-Shinozaki, K., Shinozaki, K., et al. (2005). Effects of free proline accumulation in petunias under drought stress. J. Exp. Bot. 56, 1975-1981. doi: 10.1093/jxb/eri195

Yamamuro, C., Ihara, Y., Wu, X., Noguchi, T., Fujioka, S., Takatsuto, S., et al. (2000). Loss of function of a rice brassinosteroid insensitivel homolog prevents internode elongation and bending of the lamina joint. Plant Cell 12, 1591-1606. doi: $10.1105 /$ tpc. 12.9 .1591

Yan, J., Guan, L., Sun, Y., Zhu, Y., Liu, L., Lu, R., et al. (2015). Calcium and ZmCCaMK are involved in brassinosteroid-induced antioxidant defense in maize leaves. Plant Cell Physiol. 56, 883-896. doi: 10.1093/pcp/pcv014

Yang, C., Liu, J., Dong, X., Cai, Z., Tian, W., and Wang, X. (2014). Short-term and continuing stresses differentially interplay with multiple hormones to regulate plant survival and growth. Mol. Plant. 7, 841-855. doi: 10.1093/mp/ssu013

Yang, X. Y., Zeng, Z. H., Yan, J. Y., Fan, W., Bian, H. W., Zhu, M. Y., et al. (2013). Association of specific pectin methylesterases with Al-induced root elongation inhibition in rice. Physiol. Plant. 148, 502-511. doi: 10.1111/ppl.12005

Yang, Y. W., Chen, H. C., Jen, W. F., Liu, L. Y., and Chang, M. C. (2015). Comparative transcriptome analysis of shoots and roots of TNG67 and TCN1 rice seedlings under cold stress and following subsequent recovery: insights into metabolic pathways, phytohormones, and transcription factors. PLOS ONE 2:e0131391. doi: 10.1371/journal.pone.0131391
Ye, H., Liu, S., Tang, B., Chen, J., Xie, Z., Nolan, T. M., et al. (2017). RD26 mediates crosstalk between drought and brassinosteroid signalling pathways. Nat. Commun. 24:14573. doi: 10.1038/ncomms 14573

Yu, S., Ligang, C., Liping, Z., and Diqiu, Y. (2010). Overexpression of OsWRKY72 gene interferes in the abscisic acid signal and auxin transport pathway of Arabidopsis. J. Biosci. 35, 459-471. doi: 10.1007/s12038-010-0051-1

Yusuf, M., Khan, T. A., and Fariduddin, Q. (2017). "Brassinosteroids: physiological roles and its signalling in plants," in Stress Signaling in Plants: Genomics and Proteomics Perspective, Vol. 2, eds M. Sarwat, A. Ahmad, M. Z. Abdin, and M. M. Ibrahim (Berlin: Springer International Publishing), 241-260.

Zeng, H., Tang, Q., and Hua, X. (2010). Arabidopsis brassinosteroid mutants det21 and bin2-1 display altered salt tolerance. J. Plant Growth Regul. 29, 44-52. doi: 10.1007/s00344-009-9111-x

Zhang, A., Zhang, J., Ye, N., Cao, J., Tan, M., Zhang, J., et al. (2010). ZmMPK5 is required for the NADPH oxidase-mediated self-propagation of apoplastic $\mathrm{H}_{2} \mathrm{O}_{2}$ in brassinosteroid induced antioxidant defence in leaves of maize. J. Exp. Bot. 61, 4399-4411. doi: 10.1093/jxb/erq243

Zhang, A., Zhang, J., Zhang, J., Ye, N., Zhang, H., Tan, M., et al. (2011). Nitric oxide mediates brassinosteroid-induced ABA biosynthesis involved in oxidative stress tolerance in maize leaves. Plant Cell Physiol. 52, 181-192. doi: 10.1093/ $\mathrm{pcp} / \mathrm{pcq} 187$

Zhang, C., Bai, M. Y., and Chang, K. (2014). Brassinosteroid-mediated regulation of agronomic traits in rice. Plant Cell Rep. 33, 683-696. doi: 10.1007/s00299014-1578-7

Zhang, G., Song, X., Guo, H., Wu, Y., Chen, X., and Fang, R. (2016). A small $\mathrm{G}$ protein as a novel component of the rice brassinosteroid signal transduction. Mol. Plant 9, 1260-1271. doi: 10.1016/j.molp.2016.06.010

Zhang, Y. C., Yu, Y., Wang, C. Y., Li, Z. Y., Liu, Q., Xu, J., et al. (2013). Overexpression of microRNA OsmiR397 improves rice yield by increasing grain size and promoting panicle branching. Nat. Biotechnol. 31, 848-852. doi: $10.1038 /$ nbt.2646

Zhao, F. Y., Liu, W., and Zhang, S. Y. (2009). Different responses of plant growth and antioxidant system to the combination of cadmium and heat stress in transgenic and non- transgenic rice. J. Integr. Plant Biol. 51, 942-950. doi: 10.1111/j.1744-7909.2009.00865.x

Zhao, L., Zhang, F., Guo, J., Yang, Y., Li, B., and Zhang, L. (2004). Nitric oxide functions as a signal in salt resistance in the calluses from two ecotypes of reed. Plant Physiol. 134, 849-857.

Zhiponova, M. K., Vanhoutte, I., Boudolf, V., Betti, C., Dhondt, S., Coppens, F., et al. (2013). Brassinosteroid production and signaling differentially control cell division and expansion in the leaf. New Phytol. 197, 490-502. doi: 10.1111/nph. 12036

Zhou, J., Xia, X. J., Zhou, Y. H., Shi, K., Chen, Z., and Yu, J. Q. (2014). RBOH1dependent $\mathrm{H}_{2} \mathrm{O}_{2}$ production and subsequent activation of MPK1/2 play an important role in acclimation-induced cross- tolerance in tomato. J. Exp. Bot. 65, 595-607. doi: 10.1093/jxb/ert404

Zhou, Y., Xia, X., Yu, G., Wang, J., Wu, J., Wang, M., et al. (2015). Brassinosteroids play a critical role in the regulation of pesticide metabolism in crop plants. Sci. Rep. 5:9018. doi: 10.1038/srep09018

Zhu, T., Deng, X. G., Tan, W. R., Zhou, X., Luo, S. S., Han, X. Y., et al. (2015). Nitric oxide is involved in brassinosteroid-induced alternative respiratory pathway in Nicotiana benthamiana seedlings' response to salt stress. Physiol. Plant. doi: 10.1111/ppl.12392 [Epub ahead of print].

Zhu, Y., Zuo, M., Liang, Y., Jiang, M., Zhang, J., Scheller, H. V., et al. (2013). MAP65-1a positively regulates $\mathrm{H}_{2} \mathrm{O}_{2}$ amplification and enhances brassinosteroid-induced antioxidant defence in maize. J. Exp. Bot. 64, 3787-3802. doi: 10.1093/jxb/ert215

Conflict of Interest Statement: The authors declare that the research was conducted in the absence of any commercial or financial relationships that could be construed as a potential conflict of interest.

Copyright $\odot 2017$ Sharma, Kaur and Pati. This is an open-access article distributed under the terms of the Creative Commons Attribution License (CC BY). The use, distribution or reproduction in other forums is permitted, provided the original author(s) or licensor are credited and that the original publication in this journal is cited, in accordance with accepted academic practice. No use, distribution or reproduction is permitted which does not comply with these terms. 